\title{
UNIVERSITYOF
}

FORWARD

THINKING

WESTMINSTER用

WestminsterResearch

http://www.westminster.ac.uk/westminsterresearch

\section{All in the Family? Parental Roles in the Epidemic of Childhood Obesity}

Moore, E., Wilkie, W. and Desrochers, D.M.

This is a pre-copy edited, author-produced PDF of an article accepted for publication in the Journal of Consumer Research following peer review.

The definitive publisher-authenticated version of Moore, E, Wilkie, W and Desrochers, D. (2016) All in the Family? Parental Roles in the Epidemic of Childhood Obesity, Journal of Consumer Research 2016; doi: 10.1093/jcr/ucw059 is available online:

https://dx.doi.org/10.1093/jcr/ucw059

The WestminsterResearch online digital archive at the University of Westminster aims to make the research output of the University available to a wider audience. Copyright and Moral Rights remain with the authors and/or copyright owners.

Whilst further distribution of specific materials from within this archive is forbidden, you may freely distribute the URL of WestminsterResearch: ((http://westminsterresearch.wmin.ac.uk/)).

In case of abuse or copyright appearing without permission e-mail repository@westminster.ac.uk 
All in the Family?

Parental Roles in the Epidemic of Childhood Obesity

\author{
ELIZABETH S. MOORE \\ WILLIAM L.WILKIE \\ DEBRA M. DESROCHERS
}


Elizabeth S. Moore (emoore@nd.edu) is associate professor of marketing, Mendoza College of Business, University of Notre Dame, Notre Dame, IN 46556. William L. Wilkie (wwilkie@nd.edu) is the Nathe Professor of Marketing, Mendoza College of Business, University of Notre Dame, Notre Dame, IN 46556. Debra M. Desrochers (d.desrochers@westminster.ac.uk) is senior lecturer, Westminster Business School, University of Westminster, 35 Marylebone Road, London NW1 5LS. Correspondence: Elizabeth Moore. The authors wish to express their sincere appreciation to the editors, associate editors and reviewers for their very constructive suggestions. This article is dedicated to the memory of Robert W. Moore. 


\begin{abstract}
Childhood obesity is a serious global health challenge. Families and consumption are at the nexus of the problem, as childhood weight issues depend significantly on family-related influences (genetic predispositions, physical activities, and household food consumption practices). This article focuses on how a family socializes a child toward or away from obesity. It advances a family consumer socialization framework to characterize key elements and processes. Biological predispositions, parent/family inputs, elements of child development, parent-child interactions, and intergenerational transfer are all major contributors to weight status and life course potentials. Time is also a crucial component, here represented in two forms -- linear and cyclical. Drawing on extensive research from other disciplines and related consumer research, five "Foundational Properties" are distilled, representing fundamental tenets underpinning the family's role in this problem. Each property is then used to chart promising opportunities for consumer researchers and others interested in advancing knowledge on this pressing concern.
\end{abstract}

Keywords: children, obesity, parents, family, childhood obesity, socialization, consumption 
Childhood obesity is a serious problem globally. Since 1980, there has been nearly a 50\% increase in the proportion of overweight children worldwide (Ng et al. 2014), and in the U.S. today, close to one in three (32\%) children and teens are either overweight or obese (Ogden et al. 2012). Obesity brings significant health risks - in fact, the present situation is so severe that, if levels are not reduced, the current generation of American children could have shorter and less healthy lives than their parents (Olshansky et al. 2005). And the consequences are not only physical: overweight children face bias, teasing and social marginalization, which can lead to lower self-esteem and increased risks of eating disorders, depression, and a reduced quality of life (Puhl and Lattner 2007). Childhood obesity has been characterized as an 'epidemic' by the medical community, leading to increasingly powerful calls for solutions.

When considering the scope of the problem it is important to begin by understanding that obesity is fundamentally a consumption phenomenon. It results from a sustained imbalance of energy intake in excess of expenditure, leading to storage in the form of fat, and ensuing weight gain. U.S. children have serious problems on both sides of this equation: consumption of energy (dietary intake) is too high, and expenditure of energy (through physical activity) is too low.

At the center of the problem is the family, with its overarching impact on a child's future. Whether obesity develops in a child depends significantly on family related influences (genetic predispositions, physical activity, and food consumption practices). Over time, a child develops diet and activity patterns that will protect against or heighten obesity risk - this is in the province of consumer socialization. Some families are doing well in this regard, while others are not. Key questions involve why, and what might be done better. Much is known, but much more remains to be learned. Our goal in this article is to provide a strong foundation for consumer researchers interested in contributing to knowledge on this important problem. 


\section{CONSUMER SOCIALIZATION: \\ ON THE ROAD TO CHILDHOOD OBESITY}

\section{Childhood Consumer Socialization and the Family}

Socialization, defined as the process by which individuals develop patterns of socially relevant behavior through interactions with others (Maccoby 2007), offers a useful theoretical perspective from which to examine this problem. By reinforcing particular beliefs and traditions socialization helps a society to function, and individuals to develop their personal identities. Socialization is a life-long process, and childhood is a particularly crucial period. The family of origin is widely viewed as the first and most influential socialization agent (school, media, religion, and peers are others). A predisposition to emulate the behaviors of parents, siblings and others is a strong force for socialization in the family (Grusec and Davidow 2007). Thus, the family is in a powerful position to either contribute to a child's healthy future or fail to do so.

"Consumer socialization" is a domain-specific element of socialization, defined as the "processes by which young people acquire the skills, knowledge and attitudes relevant to their functioning as consumers in the marketplace" (Ward 1974, 2). Research in this area has provided significant insight into the development of children's cognitive and social capacities, decision making skills, and comprehension of marketing activities, particularly advertising (Brucks, Armstrong and Goldberg 1988; Chaplin and John 2005; Gregan-Paxton and John 1997; John 1999; Moore and Lutz 2000; Peracchio 1992; Roedder 1981). It has informed our understanding of parent-child influence in household purchase decisions and the impacts of parenting style on 
children's learning (Beatty and Talpade 1994; Carlson and Grossbart 1988). And it has shown that childhood consumer learning has long term effects. Exposure to a brand's advertising in childhood can lead to positive evaluations of that product as an adult (Connell, Brucks and Nielsen 2014). The family's role is central here: childhood learning from parents can be remarkably resilient, shaping later outcomes such as the products consumed and the brands preferred by adults (Moore, Wilkie and Lutz 2002). And parents' giving of material goods for positive behaviors (or removal to punish) can set the stage for children to become more materialistic adults, a characteristic associated with long term overconsumption (Richins and Chaplin 2015).

Almost all research on family roles in childhood obesity has been conducted in other fields, including pediatric medicine, public health, nutrition, developmental psychology, family studies, genetics, and physiology (McGinnis, Gootman and Kraak 2006). This is a rich, complex phenomenon with many dimensions.

\section{Our Family Consumer Socialization Framework}

The Centers for Disease Control and Prevention has emphasized that a developmental context is central to the childhood obesity phenomenon and its mitigation (Esposito et al. 2009). However, obesity research in other disciplines has not focused significantly on how a child's capacities evolve (Harrist et al. 2012), nor on how these are manifested in consumption related skills. Thus there are important needs for future study at the intersection of consumer socialization and childhood obesity (Ekstrom 2006).

Figure 1 displays our basic consumer socialization framework for investigating the 
family's influence on the development of childhood obesity. The family (in all its various forms, including parents and/or other caregivers) serves as the encompassing unit of the framework, existing within its surrounding environment. Because the family's role in childhood obesity is multifaceted, viewing it from a single perspective will highlight certain features, but hide others. To comprehend a complex topic well it is helpful to walk around it mentally, adopting multiple perspectives and searching for new insights (Wilkie and Moore 1999). This is reflected in figure 1, where five sectors are represented, with pertinent issues included in each one. The sectors are numbered to reflect the order in which they are discussed in this article. At the left, Sector I, physiological predispositions, captures the "nature" elements that a child inherits from his or her parents. Some children begin their lives with tendencies toward obesity while others begin with stronger protections against it.

Insert figure 1 about here

The extent to which obesity status is subsequently realized or avoided, however, depends on the socialization processes that follow, indicating the "nurture" provided within the family system in childhood. This is represented in the center of figure 1 where three primary sectors of interest to our analysis are depicted: parents/family, parent-child interactions, and the child. Each is essential to consider, yet there is much interdependence as well as a distinction to be respected between unitary and dyadic phenomena - at times the parent or the child alone is our focus, while at other times the nature of their dyadic relationship is of key concern. We thus present them separately in figure 1 and in our subsequent discussions to bring to light facets of the problem emanating most directly from each source (the numbering of these three sectors 
reflects the ordering of the discussions to come: we begin with the child, then shift to the family unit and parents, then to the interactions among parents and child). Finally, the intergenerational transfer sector at the right side reflects the weight related 'outcomes' of the socialization process as a child prepares to leave the family setting as a young adult.

Although Sector I, 'physiological predispositions' is not seen as a focal area for consumer research, the other four sectors are quite pertinent. Our extended discussions of these four sectors are organized around "Foundational Properties" (FP), each of which offers a fundamental insight into this topic, as follows:

-- When discussing the child, the research locus is:

FP I. A Child's Internalization of Healthful Consumption Habits is a Fundamental Goal.

-- When discussing the family/parents, the research loci shift to:

FP II. Household Environments Create Differential Susceptibility to Overweight.

FP III. Parents' Misperceptions and Knowledge Gaps Pose Problems.

-- When discussing parent/child interactions, the locus is:

FP IV. Parenting Practices Serve to either Foster or Protect Against Overweight.

-- When discussing intergenerational transfer, the locus is:

FP V. The Roots and Sustaining Forces Supporting Childhood Obesity are Intergenerational in Nature.

The bottom of figure 1 portrays additional important elements of this framework: the multidimensional representation of time. Following Daly (1996), two forms of time are operative. Linear time runs from left to right, reflecting that socialization occurs on a continual basis as a child develops physically, cognitively, socially, and emotionally from birth to age 19 (early adult autonomy). Households evolve across time as well: both children and parents progress through the life cycle, and a family's structure can itself be shifting with changes in marital status, as well as the entry and departure of family members (Epp and Price 2008; Epp, Schau and Price 2014). Such events can alter how a family manages daily diet and physical activity routines, either positively or negatively. Simultaneously, children are maturing, taking 
on new responsibilities and seeking greater autonomy, leading to renegotiations of the parentchild relationship in adolescence. The nature of parent child interactions thus evolves across time, with new socializing influences also emerging from the larger environment. A second form, cyclical time (or “circular time," Daly 1996) is also fundamental, as it represents repetitive actions or routines enacted across linear time. Embedded within is 'family time' (Daly 2001; Epp and Price 2012), which often governs the child's accumulation of thousands of individual consumption related episodes involving food and physical activity.

Our socialization framework thus underscores the fact that childhood obesity, though typically assessed as a state measure, actually emerges through a child's genetic heritage and evolves through multitudinous consumption episodes. In the early years, a young child is not so much making consumption 'decisions' as learning 'lessons.' Some of these lessons arise from parents' intentional socialization behaviors, but others ensue even when parents are unaware of their influence (Ward 1974). Overall, the family's practices in the domains of physical activity and food consumption help to produce well-trodden paths of preferences and behaviors for the child, some habitual in nature, and weight issues will either arise or be controlled through these. And, with respect to weight, some early preferences and habits will extend into adulthood, as obese children are likely to become obese adults (Freedman et al. 2005b). To set the stage for our investigation of these developments, however, we first sketch some essential background on the biological underpinnings of obesity, as depicted in Sector I at the left side of figure 1.

\section{PHYSIOLOGICAL PREDISPOSITIONS}

A child's risk for obesity begins with biological proclivities inherited from his or her 
parents. Geneticists have found a strong heritable component to obesity in twin and family studies (Bouchard 2009). These propensities make it especially difficult for some children and their parents to cope with what has been termed our 'obesogenic' environment - one promoting sedentary behavior and excessive food consumption (Swinburn, Egger and Raza 1999). It is important to note that children are born with an innate capacity to regulate their food intake based on hunger cues, which serves as a natural protective factor against obesity (Fox et al. 2006). Over time, however, they become increasingly responsive to what the external environment signals about what and how much to eat, and rely less on their internal signals.

The biological etiology of overweight has been much studied recently, with discoveries of hormones (e.g., leptin, insulin) that help to regulate appetite (Skelton et al. 2011), and genes or chromosomal regions linked to obesity. Forty-two genes (and increasing in number) are now associated with BMI (Manco and Dallapiccola 2012). Humans inherit universal tendencies such as a predisposition to reject sour or bitter tastes (protecting against ingestion of toxins) and to prefer sweet or salty tastes (Savage, Fisher and Birch 2007). Family genetics then lead to taste sensitivities: for example, only some people inherit genes enabling taste of certain bitter compounds such as phenylthio-cabamide (PTC). Tasters of PTC have more food dislikes in general, including the taste of high fat foods (Garcia-Bailo et al. 2009). There are heritable components in children's preferences for fruits and meats (Breen Plomin and Wardle 2006), and specific macronutrients, chiefly dietary fat (Reed et al. 1997). Appetite related traits such as food cue responsiveness and eating rate also have a genetic basis (Carnell et al. 2008; Llewellyn et al. 2008). And some children are genetically less attuned to physical signals of satiation, thus are at greater risk of overeating and more likely to become obese (Faith, Carnell, and Kral 2013). Genetics also influence children's differential reactions to parental feeding styles: what works 
well for most children can be ineffective for those at high risk for overweight (Faith et al. 2004).

Genetics impact physical activity through genes associated with dopamine, a neurotransmitter for reward and pleasure centers of the brain that helps govern movement and emotion, and beta-endorphins, neurotransmitters that interact with brain cell receptors involved in blocking pain and controlling emotion (Lightfoot 2011). Obese adults are more likely to have a genetic variation (the Taq1A1 allele) linked to fewer dopamine D2 receptors on cells (Epstein, Dearing and Erbe 2010). They must take in more of a rewarding substance, such as food, to obtain the satisfaction impact others have already received, also a challenge to weight control.

Thus childhood obesity is rooted in genetics, pointing to a central role of the family. However, genetics is not solely responsible for the current epidemic, as the gene pool in the United States population changes very slowly (Koplan and Dietz 1999). Researchers are now using bio-behavioral risk models to examine complex interactions among genetics, metabolic characteristics, and environment (Carnell, Kim and Pryor 2012). Not all individuals with these genetic propensities actually do become obese. Thus the manner in which a family socializes a child regarding diet and exercise is crucial in determining future outcomes (Dubois et al. 2012). To investigate this issue we now focus on Sector II, the child, as depicted in the lower portion of figure 1.

\section{FOCUSING ON THE CHILD}

The increase in childhood obesity is a relatively recent phenomenon in the U.S., with dramatic changes occurring in the 1980s and 1990s, and a general plateauing of incidence from 1999 to 2010 but at dangerously high levels (Ogden et al. 2012). As noted earlier, childhood 
obesity is the result of a sustained energy imbalance. With regard to energy intake, dietary data are bleak. Only one in five youth $(21 \%)$ consume recommended daily servings of fruits and vegetables. Yet, $40 \%$ of the calories children consume are 'empty calories' due to solid fats and added sugars (about half of these from six popular foods - soda, fruit drinks, dairy desserts, grain desserts (cookies, cake), pizza and whole milk) (Reedy and Krebs-Smith 2010). And with respect to energy expenditure, the majority of youth fail to meet the federal guideline of 60 minutes of moderate to vigorous physical activity each day (Eaton et al. 2010). Only $42 \%$ of 6-11year olds achieve this level, and a sharp decline occurs in adolescence, with only $8 \%$ of teens (ages $12-19$ ) this active (Troiano et al. 2008). Thus, at a population level the consumption of food and physical activity is clearly out of balance, leading many to overweight or obese status.

Such imbalances do compromise physical health. Medical problems are common in obese children, affecting the cardiovascular (hypertension, blood cholesterol) and endocrine systems (Type 2 diabetes), with further threats to the pulmonary (asthma, sleep apnea), orthopedic, and gastrointestinal systems (Han, Lawlor and Kimm 2010). Overall, $70 \%$ of obese children ages 517 have one cardiovascular risk present, and 39\% have two or more (Freedman et al. 2007).

Developmental Considerations: Ethnic Differences and Weight across Time

U.S. children are not at equal risk: about one in four Black, one in five Hispanic, and one in seven White children and teens are obese (Ogden et al. 2012). Males are slightly more prone to obesity than females (19\% v. 15\%), but this disparity is driven by White males and females (16\% v. $12 \%$ ), as levels are not significantly different by gender among either Black or Hispanic youth. 
Insert figure 2 about here

As shown in figure 2, the development of obesity during maturation is not simply linear. Moreover, hidden within these age groups are critical periods in which a child is particularly vulnerable to weight gain. BMI increases in an infant's first year, declines for the next four or more years, then hits the critical "adiposity rebound" period beginning between ages five and seven. Children who start this process earlier (at age 5) will likely maintain higher BMI's into their teen and adult years (Dietz 1994). Adolescence, with its changes in body composition and size, is the next critical time, especially for females (adiposity increases at ages 12-14, then declines, with males facing a smaller rise about age 14, followed by decline). Many factors impinge on a child's weight (Potter and Ulijaszek 2013), but research does show carryover from early childhood into adulthood: one study reported the chances for being an obese adult if obese as a child ranged from $65 \%$ for White girls to $84 \%$ for Black girls, and $71 \%$ and $82 \%$ for boys (Freedman et al. 2005a). Thus parents need to be vigilant about their child's weight status from a young age.

Foundational Property I: A Child's 'Internalization' of Healthy Consumption Habits is a Fundamental Goal.

Effective socialization requires more than behavior that simply complies with parental demands (Grolnick, Deci and Ryan 1997). Internal adaptation and acceptance has to occur for positive values to become integrated within the child's sense of self. To forestall obesity, a child should internalize values and behaviors that enable a healthy lifestyle. We stress the significance of 
this concept by naming it as the first 'Foundational Property,' and now delve into this area to consider what is known, and what is still to be learned. Topics that consumer researchers might pursue are highlighted in figure 3.

Insert figure 3 about here

Internalization is the process by which "individuals acquire beliefs, attitudes or behavioral regulations from external sources and progressively transform those external regulations into personal attributes, values or regulatory styles" (Grolnick et al. 1997, 139). This process begins with a child's behavior being motivated by external contingencies (requests, rewards, demands) imposed by parents and other caregivers: here a child need only respond. Next is 'introjected regulation,' where external rules are taken in, but behavior is still seen as controlled by others. Following is 'identification,' where the child views a behavior as relevant to personal goals, thus perceiving a greater sense of choice. Finally, 'internalization' occurs when a belief or behavior is assimilated with other aspects of the self, contributing to a coherent system of motives and goals. Although children have an inherent proclivity toward some positive behaviors, others may not be naturally rewarding (e.g., eating vegetables, avoiding sugary snacks, limiting TV). Thus appropriate conditions need to be in place in the home to foster healthy behavior.

Developing Food and Exercise Habits: For Better or For Worse? Our first entry in figure 3 represents a distinct research possibility that has not yet been much pursued in childhood obesity studies. If we think about it, we can easily see that a child's consumption within the family is often repetitive, occurring at regular times (e.g., dinner), in specific settings 
(kitchen table), and associated with specific cues (cooking aromas). Such repetition gives rise to a child's development of habits, which are learned responses to situational cues that have been rewarded by satisfactory experiences in the past, and which are triggered automatically by specific environmental cues (van't Riet et al. 2011). Automaticity is a significant feature of habit, with perception of the contextual cue directly activating the learned response without conscious consideration and at times without awareness (Wood and Neal 2009). Research on adults has shown that habit strength is a powerful predictor of food consumption, including snacks, fruits and vegetables, meat, fish, and soft drinks (van't Riet et al. 2011) Thus the development of healthy habits by a child can provide valuable protection against obesity.

At the same time, automaticity means that bad habits can be hard to undo. Strategies possible for parents are organized around: (1) changing the situational cue, (2) training a new healthy response (e.g., snacking means an apple rather than candy) or inhibiting prior responses (no candy in the pantry), and/or (3) providing new rewards for healthful actions (van't Riet et al 2011). Consumer researchers can add much understanding of which consumption related habits children tend to develop, and how parents are contributing.

Development of Self-Control as a Protective Factor. The child's development of selfcontrol (also termed self-regulation here) is identified in figure 3 as the second area in need of research. Self-regulation can involve processes such as the ability to direct and sustain attention, to inhibit automated reactive responses, and to impose cognitive and behavioral controls as needed (Baumeister and Vohs 2004). Considerable research in developmental psychology has been devoted to children's self-regulatory abilities, broadly defined as a child's conscious or unconscious efforts to control or alter inner states or responses (Frankel et al. 2012). In a classic 
study, Mischel and Mischel (1983) showed that the ability to delay gratification (i.e., "you can eat the marshmallow if you ring the bell to bring me back, or you can eat two if you wait until I return”) develops with age. Given this instruction, most preschoolers opt to leave the treat visible and repeat a phrase about its great taste. Most third and sixth graders know that it is better to have the food out of view, and rehearse their goal to wait. Successful delay involves attentional control and an ability to inhibit the urge to take the reward. It may also activate impulsive reactive tendencies, which can be difficult for some children to resist (Eisenberg et al 2004).

As noted earlier, physiological factors can be at work here. For example, a dopaminergic dysfunction may interfere with a child's satiety signals, leading to preference for foods high in fat and sugar (Graziano et al. 2013). As predicted, toddlers high in this tendency were more likely to be overweight later, at age 10 . Would stronger self-regulatory skills have helped? Research suggests that they would. Francis and Susman (2009) found that children with a greater ability to self-regulate at ages 3-5 had lower BMI scores up to age 12. And the power of selfregulation may persist across decades. Mischel recontacted the marshmallow study participants 40 years later, and concluded that self-control indicators in preschool "appear to be important early life markers for long term adaptive ...development" (Mischel et al. 2011, 255). A surprisingly wide range of psychological, health and economic outcomes were affected. Development of self-regulation is thus of central importance as protection against obesity.

The Depletion of Self-Control: Use of EAH. One of the ways that children's self-regulatory failures may be manifested is through disinhibited eating behaviors. Of special interest here is 'eating in the absence of hunger' (EAH). As a behavioral measure of disinhibition, EAH reflects the tendency to consume large amounts of appealing foods in a short time, irrespective of hunger 
(Hill et al. 2008). EAH research is grounded in Schachter's (1968) early findings that obese people are more sensitive than others to food cues in the environment. Among children and adolescents, EAH has repeatedly been linked to obesity, found to persist over time, and be related to individual differences (Boutelle et al. 2014; Francis et al. 2007). Such differences may be grounded in exposure to particular family eating styles, and also in one's biological predispositions. For example, twin studies show that a normal weight twin is less likely to engage in EAH than an obese sibling, suggesting an impaired ability to regulate caloric intake by the overweight twin (Kral et al. 2012). We note that EAH has not been employed in consumer research to date, and should be considered due to its potential for gaining insight into children's responses to both home and external food environments.

While consumer researchers have not examined EAH in children, they have explored adult self-regulation or control, often in the context of food choice. Self-control is often characterized as a response to psychological conflict between desire (indulge now) versus willpower (delay for health) (Hoch and Lowenstein 1991). Multiple theoretical perspectives have been adopted, with some researchers primarily focused on desire (Redden and Haws 2013) and others on willpower (Hung and Labroo 2011). Effective self-control is thought to depend on: (1) having clear goals, (2) behavioral monitoring, and (3) a capacity to change (Baumeister 2002).

According to Baumeister (2002), self-control becomes depleted when used, making it more difficult to exert self-control in a subsequent decision. Consumer researchers have evidenced theoretical interest in ego depletion (e.g., Vohs and Faber 2007; Wan and Agrawal 2011) and debate about its boundary conditions (Dewitte, Bruyneel and Geyskens 2009). This issue is relevant for parent-child interactions as well as for the individual child. Consider, for example, a mother facing repeated requests for snacks during the day: will she become depleted and 
eventually succumb, or stand firm consistently? Her actions have implications for a child's shortterm food intake, but also for the child's learning. To learn to self-regulate effectively, children need to develop 'effortful control,' the capacity to willfully inhibit, activate or moderate their attention and behavior. A mother's ability to respond constructively, express positive emotions, and be patient is predictive of a child's level of effortful control (Eisenberg et al. 2004). As noted in figure 3, it would be helpful for consumer researchers to extend prior research to study depletion of self-control in both children and their parents, perhaps employing EAH measures.

Managing Emotions in Self-Control. Another element in developing self-control is the child's ability to regulate emotions - to delay gratification, tolerate frustration, curb impulses, and express emotions in socially acceptable ways (McCabe, Cunningham, Brooks-Gunn 2004). Food is a domain with rich emotional meanings, yet there has been little study at the intersection of children's emotional self-regulation, parental influence and obesity (Frankel et al. 2012).

Again consumer researchers possess potentials to contribute, as they have offered insights into adults' management of emotion and food that could be extended to parents' behavior as well as how children are socialized in this regard. Consumer research has shown, for example, that mood affects adults' healthy food choices (Garg, Wansink and Inman 2007), and that indulgent decisions are more likely when trying to maintain a happy mood or fix an unhappy mood (Labroo and Mukhopadhyay 2009). Further, positive emotions linked to the future (e.g., hopefulness) lead to healthier food choices than those focused on the past or present (Wilcox, Kramer and Sen 2011; Winterich and Haws 2011). Emotion is, moreover, not only an input to, but also a consequence of, food decisions: the simple act of exerting self-control can increase anger related behaviors, particularly among restrained eaters (Gal and Liu 2011). 
The emotional ties and uses of food that are learned can impact a child well into the future, and parents could benefit from better insights. For example, parents model emotions, sometimes deliberately, but often unintentionally. Consider the child who repeatedly observes her mother eating ice cream to bolster a sagging mood or who, after resisting the treat, seems angry at everyone around her. Additionally, a parent's reactions to a child's emotional expressions about food can be important (Frankel et al. 2012). A frustrated or angry response when a child refuses to eat broccoli may increase the negative emotion the child associates with this vegetable. Conversely, if cake and ice cream are consistently linked to happy family occasions, the positive emotional qualities of such treats are enhanced. As noted in figure 3, integrative research on children's emotional self-regulation, food, and obesity is needed. Frankel et al. (2012)'s review of emotional regulation in children can provide a useful starting point for this endeavor.

Dispositional Difficulties in Self-Control: The Concept of Temperament. While dietary self-regulation is crucial to combat childhood obesity, some parents face more constraints than others in helping their child achieve this goal. A child's temperament is prominent among these, yet has been surprisingly understudied in obesity research (Bergmeier et al. 2014). Temperament refers to individual differences in a child's behavioral style, reflecting traits such as adaptability, persistence, distractibility, emotionality, and intensity (Carey, Hegvik and McDevitt 1988).

Children of particular temperaments have difficulties accepting dietary changes when introduced, and they may overeat (Agras et al. 2004; Zeller, Bolles and Reiter-Purtill 2008). These issues surface early in life. Irritability in infancy predicts later carbohydrate intake in toddlers (Wells et al. 1997), and high levels of emotionality and shyness in preschoolers predict an unwillingness to try new foods (Pliner and Loewen 1997). Parents of an irritable child might 
find themselves using sugary treats to soothe, while parents of a shy child might find it hard to serve non-preferred vegetables. And when siblings are present, parents may need to approach each child differently (Webber, Cooke and Wardle 2010).

Impulsivity is one characteristic of temperament that has repeatedly been tied to obesity. (Anzman and Birch 2009; Van den Berg et al. 2011). Impulsive children exhibit externally motivated, emotional eating, but, notably, not when parents monitor them (Farrow 2012). Temperament's tendencies are not always expressed, but require the right eliciting conditions, and the parent-child relationship is fundamental in this respect (Bates and Pettit 2007).

Figure 3 notes a special need for research to better understand dispositional variation across children in their self-regulatory capacities. Consumer studies of traits related to adults' food choices can assist here. For example, adults higher in self-control satiate faster on unhealthy foods than healthy foods (Redden and Haws 2013), and a chronic prevention focus abets selfcontrol through the use of mental budgets when faced with temptation (Krishnamurathy and Prokopec 2010). Although poor self-control occurs across domains (e.g., food and spending, Faber et al. 1995), adults who think about the consequences of their behavior, or 'elaborate on potential outcomes,' can exercise greater self-control (Nenkov, Inman and Hulland 2008).

Adult impulsivity, as with children, seems to create both a tendency to overeat and a higher propensity to 'switch' between indulging in a forbidden food and resisting it. Why? According to Ramanathan and Williams (2007), adults feel immediate pleasure in indulging, but also frustration for having succumbed. Prudent consumers also experience guilt and regret. As their positive feelings fade, these consumers may be left with the negative emotions and thus less likely to indulge later. For impulsive consumers, conversely, the negative emotions dissipate quickly, leaving them with more positive feelings after indulging. Consistent with this 
explanation, impulsive consumers can be helped to resist temptation if encouraged to recall past episodes of having indulged (Mukhopadhyay, Sengupta and Ramanathan 2008). Given such rich findings, it would be useful to extend this work to assess when in a child's development such characteristics are operational, on what cognitive and emotional skills they depend, and what parents can do to aid the internalization of positive dispositions.

Developmental Progression in Children's Understanding of Weight and Health.

The internalization process is consistent with consumer socialization research showing how children's capacities for multidimensional and contingent thinking, grasp of social meanings and abstract reasoning develop with age (John 1999). As indicated in the third section of figure 3, it also raises a basic question: What do children know about healthy living and obesity, and how does this understanding develop? The success of the internalization process rests, in part, on a child's grasp of these issues, but little attention has yet been given to this topic. In a focus group study, overweight youth (grades 4-8) did view obesity as a general problem, but many failed to see it in themselves, connect it to their own diet and activity, or perceive its negative health effects (Syletsky et al. 2013). At what ages can children effectively cope with these risks?

With regard to interventions, which weight management strategies that assist adults can be modified for children at different developmental levels? For example, Townsend and Liu (2012) found that planning one's diet enhances self-control, and suggest strategies such as individuallycustomized plans, stocking only planned foods, and supplying one's own snacks. Could these be adapted for children and teens? Relatedly, Hoch and Lowenstein (1991) suggest three adult tactics to reduce desire -avoidance, substitution, and 'postponement and distraction.' Parents' 
efforts to avoid having certain foods in the home, and substitute healthy, appealing foods could be effective, but the third approach demands more analytical thought than present in young children. However, as cognitive function develops, self-control strategies such as mental budgeting (e.g., two desserts per week) that require: (1) a clear standard for behavior, (2) an ability to consider reasons to avoid temptation, and (3) a capacity to monitor success (Krishnamurathy and Prokopec 2010) might be taught. Such plans could aid parents in their own lives, and also be useful tools for teaching their children.

The third research topic in this area centers on 'weight locus of control' - the degree to which a child believes weight is predetermined versus under one's own power. This appears to be a type of 'lay theory,' related to the concept of self-efficacy studied by consumer researchers. When and how do a child's beliefs about his or her capacity to control one's weight destiny develop, are these beliefs amenable to change, and what are parents' roles in the process? Research shows that lay theories of self-control do have real impacts on behavior (Mukhopadhyay and Johar 2005). Parents who believe self-control is finite restrict child access to unhealthy snacks more than parents who believe self-control is either unlimited or unmodifiable (Mukhopadhyay and Yeung 2010). How such parental decisions contribute to a child's own development of self-control has not yet been studied. Having spoken to some central factors within the child, we now shift our focus to Sector III, the parent and the family, represented at the top of figure 1 .

\section{FOCUSING ON PARENTS AND FAMILY}

There is little question that one's family has a substantial influence on a child's probability 
of becoming obese. For example, controlling for daughters' weight at age five, one longitudinal study found that girls with two overweight parents were eight times more likely to be overweight at age 13 than those with neither parent overweight (Francis et al. 2007). Familial resemblance for obesity results from the interplay of genes and environment, thus can be affected by a child's living arrangements. Today just $60 \%$ of American children (under 18) live with both biological parents (Kreider and Ellis 2011). Twenty percent of children and teens live in a single-parent family, and the remaining $20 \%$ in a range of step-family, cohabitation, and fosterfamily/institutional settings. Further, age at marriage is at an all-time high, cohabitation is the most typical first union, and close to $40 \%$ of births are to unmarried women (Olson 2011).

This helps to explain why no universal definition of family on which scholars can agree exists today (Galvin, Braithwaite and Bylund 2015). We adopt here an inclusive definition to reflect the varied forms and lifestyles of contemporary families: "networks of people who share their lives over long periods of time bound by ties of marriage, blood, law or commitment, legal or otherwise, who consider themselves as family and who share a significant history and anticipated future of functioning as a family" (Galvin et al. 2015, 8).

\section{Family Identity}

Whatever its structure, a family holds a distinctive identity or subjective sense of itself as special and unique (Epp and Price 2008; Sillars 1995). This collective identity is co-created and sustained through family routines and rituals, sharing of stories, enactments of social dramas and intergenerational transfers (Epp and Price 2008; Fiese et al. 2002). An important contributor is 'family time,' a type of cyclical time within our socialization framework. Family time reserves 
moments for shared activities, providing structure and meaning for child and parent alike (Epp and Price 2012). Through daily interactions a culture emerges about what it means to be a part of this family, and what members are expected to say and do (Ronka and Korvela 2009). These are the implicit theories that families live by, but they are often hidden from outside view (Daly 2003).

Consumption practices play central roles in shaping what families do. Most pertinent are some seemingly mundane activities of daily life such as shopping, meal planning, cooking and dining, as well as family outings and leisure time use. These can become habit-driven, develop a momentum of their own and may not often be questioned (Grusec and Davidow 2007). They differ by family, and act to foster or hinder the development of childhood obesity.

To understand how families function, communication scholars often adopt systems theory as a root metaphor (Galvin, Dickson and Marrow 2006). The family is characterized as a goalseeking, self-regulating social system larger and more complex than the sum of its individual members. Multiple interactions occur simultaneously among subsystems (e.g., mother-daughter) embedded within the family unit: each person influences and is influenced by the actions of the others. Children learn continuously by observing, and by participating in family activities. This is a highly interdependent system: a change in any one relationship can affect the entire family.

Not surprisingly, a family's goal management process can at times be complex. To illustrate, in planning a family vacation the family's collective goals, relational goals and each individual's goals are all active, with synergy or discord needing to be resolved (Epp and Price 2011). With regard to obesity, health researchers have recommended that systems theory be used to design interventions (Berge and Everts 2011), informing the choice of family level versus child specific variables in future research designs. 
Foundational Property II: Household Environments Create Differential Susceptibility to Overweight.

There are systematic contributors to the differential susceptibility of children and their families to obesity. Some are primarily structural in nature and others are grounded in culture.

Family Structure. Consideration of family structure is important given the diversity of children's current living arrangements in the U.S. The impact of family structure on children's development has been much studied, generally concluding that children are better off with two biological parents present, owing to a higher standard of living, greater social support and reduced stress levels (Amato 2005). Until recently, however, little was known about the influence of family structure on children's physical health (Bzostek and Beck 2011).

Childhood obesity research has been heavily focused on mothers, so the impacts of other family members, including fathers, are not well understood (Fraser et al. 2011; Hall et al. 2011; Mallan et al. 2014). However, it is clear that children in some types of families are at particular risk for obesity. Longitudinal studies show that children living with a single mother are more likely to be obese than those in two parent households, a result thought to be due to economic, social and time constraints that make a healthy lifestyle more challenging to achieve (Schmeer 2012). Siblings can mitigate this effect though by offering social and emotional support, as well as partnership in physical activities: this is intriguing for future study given only limited research investigating siblings' influence on obesity (Senguttuvan, Whiteman and Jensen 2014). The role of nonresident fathers has also been probed, finding that when these fathers are more involved in their teen's lives (time spent together, number of shared activities, level of emotional closeness), 
the risk of obesity actually increases. This effect is greater for girls, and exacerbated when the father is obese or has limited education (Menning and Stewart 2008). Explanations offered are the 'Disneyland' nature of nonresident fathers' involvement, and the challenges of pursuing a healthy lifestyle when a teen splits time between two households. The impacts of other family configurations such as step or blended families on child weight have not yet been studied.

With respect to future research, the top section of figure 4 highlights family structure issues of interest. In addition to topics already discussed, children are experiencing a greater number of family disruptions than did earlier birth cohorts. Obesity researchers have started to focus on the cumulative impacts of family transitions (termed 'family instability') as marital or cohabitating relationships are created and dissolved (Hernandez et al. 2014). Both the start and dissolution of relationships create stresses and disruptions in family routines (e.g., family meals, planned activities, sleep schedules), changes in parental involvement, emotional eating, and overconsumption. As the number of family transitions a child experiences increases, so does the risk of obesity in young adulthood (Hernandez et al. 2014). However, this pattern is evident only for young women: it is yet unclear why males and females are differentially affected.

Insert figure 4 about here

Additional questions involve family configurations (e.g., blended families), and the impacts of internal family dynamics. Future research might also consider the timing of household transitions (recent vs. distant past, critical periods for weight gain), as well as potentials for children's positive health outcomes. Until now reliance has been on surveys, experiments and focus groups. Ethnographic research could provide deeper insights into the lived experience of 
parents, children, and other family members facing weight challenges. This would afford richer conceptual models, and also assist in the design of family based interventions.

Living in Poverty. Another set of factors placing children at differential obesity risk relate to a family's socioeconomic status (SES). In developing nations obesity occurs more often in higher socioeconomic groups, where overconsumption and under-nutrition coexist (Van Hook and Balistreri 2007). In contrast, in the U.S. a disproportionate number of obese children live in poverty, intersecting with ethnicity and gender to produce important differences. Among White children household income is inversely related to obesity- $21 \%$ of boys and $18 \%$ of girls from poorer households (income $<130 \%$ of the poverty level) are obese, versus $10 \%$ of boys and $11 \%$ of girls from wealthier households (income greater than $350 \%$ of poverty level). However, income does not differentiate obesity for either Black or Hispanic youth. Thus, what constitutes an effective intervention will likely vary by demographic group (Grier and Moore 2012).

Delving into poverty, poor consumers face economic, physical and marketplace limitations that can affect their ability to eat healthfully and engage in physical activity (Andreasen 1975). Food insecurity, employment stability, availability of safe play areas, and access to supermarkets with high quality food options are factors (Andreasen 2006; Eisenmann, et al. 2011; Talukdar 2008). In 2012, $10 \%$ of U.S. households with children were estimated to be food insecure, indicating problems with either the quality or quantity of food available at some point during the year. In periods of insecurity families may need to substitute cheaper foods that are higher in calories and lower in nutritional value, then overconsume later when food is plentiful (Polivy 1996; Seligman, Whiteman and Kushel 2010). When food shortages exist, younger children may be partially protected by parents, particularly mothers, who often restrict their own intake to 
provide food for them (Bruening et al. 2012). Older children, on the other hand, are more vulnerable and may experience hunger akin to adults' (Anderson, et al. 2014). Two types of food insecurity are distinguished. 'Very low' food security families experience problems with the quantity of food available, as well as its quality, variety, and desirability. In 'low' food security families, the quality of their diet is compromised but quantity is not a problem (Bickel et al. 2000). Not surprisingly, longitudinal data indicate that it is children in the 'low' food security homes who are at greatest risk for obesity (Metallinos-Katsaras, Must and Gorman 2012).

Employment is also a factor, with studies showing a positive relationship between mothers' employment and childhood obesity across demographic groups (Morrissey, Dunifon and Kalil 2011). Employment scheduling and time constraints can affect some low income parents' ability to prepare healthy meals (Omar, Coleman and Hoerr 2001). Also, because families can move in and out of poverty, researchers have started to investigate the effects of the accumulation of poverty during childhood. Such a focus is consistent with life course perspectives that show a child's long term experience with poverty has detrimental health impacts (Evans et al. 2012). Again, however, ethnicity and gender are relevant: recurring poverty in childhood is positively associated with overweight in young adult Black, White and Hispanic women but unrelated in Black and Hispanic men, and inversely related in young White men (Hernandez and Pressler 2014). Extending research to parenting issues in impoverished settings is warranted.

Cultural Impacts and Segmentation Research. This section continues interest in ethnicity but now looks beyond poverty. According to the Pew Research Center (2011), U.S. population growth in the first decade of the 21 st century was driven almost exclusively ( $91 \%$ ) by racial and ethnic minorities, whose families tend to be younger and include more children. Differences in 
cultural beliefs and practices related to diet and weight seem to be contributing to differences in childhood obesity levels (the "socio-cultural environments of some U.S. ethnic groups appear to favor obesity development” Kumanayika 2008, 66). For example, in some groups overweight may only be seen as a problem when it is associated with health difficulties (Kumanayika 2008).

Parents are grounded in multiple subcultures that can each exert influence on food preferences, attitudes toward exercise, and beliefs about parenting (Grier and Moore 2012). The broader cultural context of food and exercise instilled in them is now being transmitted to their children through the socialization process. This influences the foods a child learns to prefer, as well as norms that are communicated (and ultimately internalized) about consumption itself including what, when and how much to eat and where, when, and how much to exercise.

Consumer research brings an extensive background to these issues and, as shown in figure 4, many research options exist. Such pursuit could employ ethnographic, sensitization (Pettigrew and Pescud 2013), or other qualitative methods to delve into food preferences, dining rituals, physical activity choices, or how body image perceptions are transmitted within the family. Studies of consumption in situ have a capacity to surface factors previously overlooked, but that are potentially modifiable. Structural barriers merit study as well. For example, in sectors of the Latino community parents' limited nutrition education, coupled with language barriers, lead to little use of food labels and difficulties in adopting healthy feeding practices (Slusser et al. 2012).

We close this section by noting that shifting demographics, changes in family structures, and differential obesity rates all point to a need for research drawing on the principles of market segmentation. Although obesity researchers do use demographic descriptors, consumer research brings expertise in a wider array of segmentation bases that could offer richer insights than demographics alone. Here we propose two broad avenues of approach. As noted in figure 4, one 
segmentation approach would expand the emphasis on culture and ethnicity by exploring further differences between these groups. Significant group differences in ideal body image (size and shape) appear as cultural norms, for example, though within group differences also exist and need to be understood (Grier and Moore 2012). Or, new research could build on past studies of parenting practices in specific subcultures (e.g., O’Dougherty, Story and Lytle 2006), a topic centered on interactions between parent and child, and discussed in this article's fourth section.

Our second avenue for segmentation research would strive to distinguish those children or families with a weight problem from those without, and then explore a range of relevant characteristics that differentiate these groups. This research could be applied at the family level (assessing family structure, economic circumstances, dietary and physical activity norms, etc.) or at the child level (assessing gender, psychological characteristics, etc.). We now turn from who these parents are to what they know or believe.

Foundational Property III: Parents' Misperceptions and Knowledge Gaps Pose Serious Problems.

Parents' Misperceptions of Weight Status. If parents are to help their obese children to lose weight, they must first realize that there is a problem. Those who do not see a problem are unlikely to address it. Yet research shows that millions of parents fail to recognize that their child is overweight, even when it is obvious to others (Doolen, Alpert and Miller 2009).

How much misperception exists? U.S. estimates vary, from $32 \%$ of mothers misclassifying their overweight 2-11 year old child as "just about the right weight" to a high of 79\% among mothers of overweight preschoolers (Baughcum et al. 2000; Maynard et al. 2003), a pattern evident across ethnic groups (Dammann, Smith and Richards 2011). Other nations report similar 
levels, with rates between $40 \%$ and 75\% (Vuorela, Saha and Salo 2010; Warschburger and Kröller 2009; Wen and Hui 2011), hence emphasizing the global nature of this phenomenon. Key moderators do exist however. Parents are more likely to misclassify younger children, perhaps believing that a child will outgrow 'baby fat' (Eckstein et al. 2006; Vuorela et al. 2010). They are less accurate in predicting their sons' weight status, possibly due to the fact that higher muscle mass raises BMI score (Tschamler et al. 2010). And the degree of overweight affects perceptions, with parents of the most obese children much more accurate (Maynard et al. 2003).

Why, though, do these misperceptions persist, and are they actually errors? Little empirical evidence exists, but explanations have been advanced. For instance, some parents may not know how 'overweight' is defined (Doolen et al. 2009). And desensitization may be occurring as excess weight becomes more of a cultural norm. This is consistent with research showing that parents are more likely to classify normal weight children as 'thin or underweight' than in the past (Luttikhuis, Stolk and Sauer 2010), and are now less accurate in their predictions than parents were a generation ago (Hansen et al. 2014). Further, some parents believe their child's size is biologically determined and beyond their control, thus making pediatric growth charts 'irrelevant' (Jain et al. 2001). Motivational factors may also be at work, with some parents reluctant (consciously or not) to admit their child has a weight problem. This is in accord with the finding that parents are better at identifying excess weight in unrelated children (Warschburger and Kröller 2009). Negative judgments about one's parenting ability may also be lurking if a child is judged to be overweight (Jain et al. 2001).

Asking why parental misperceptions exist leads to the research questions listed in the second half of figure 4. First, are these numbers an accurate reflection of reality? Studies documenting this effect have tended to use self-report verbal measures. If some parents are 
hesitant to report a weight problem, overstated levels of misperception would result. Eckstein et al. (2006) found lower misperceptions with pictorial measures than written scales, suggesting that parents are better at visually identifying their child's weight status. Another possibility is they simply do not apply an 'overweight' label to their child: whether this reflects negative connotations or a lack of understanding is not clear. Resolving such issues will help to determine who actually holds various types of misperceptions, and why they do.

How do parents assess a child's weight status? Little research has probed the underlying perceptual process, and lay theories about good parenting may be barriers. For instance, a mother praised by relatives for her chubby toddler might not be so vigilant about weight problems, nor might parents who believe 'as long as my child is active, he's fine.' Guidance on lay theories is given in St. James, Handelman and Taylor (2011), who explore 'magical thinking' in coping with weight problems (they report that 'magic' is not so much about mysterious forces as it is maintaining ambiguity about possibilities, thus sustaining hope). More generally, Wang, Keh and Bolton (2010) explore the role of lay theories of medicine in guiding consumers' health behaviors. Extensions to explore parents' lay theories about their child's weight would be useful.

This also raises the issue of parents' willingness to face the problem of overweight. Will parents accept that their child is at risk if explicitly told? Institutional communication channels are available through schools and medical practitioners, and could be a key to combatting the epidemic. In fact, in 2007 the American Medical Association and Centers for Disease Control advised doctors to hold such discussions with parents (Barlow 2007). A follow-up survey (Rausch, Peritio and Hametz 2011) found physicians' reluctance to raise the issue was receding, but perceived effectiveness was still a barrier. Over $75 \%$ of doctors rated their counseling efforts as only "a little" or "not at all effective": less than one in four answered "somewhat effective" 
and not one "very effective" rating was given. Persuasive communication research (Friedman and Churchill 1987) could help to develop and test scripts for use in these parent meetings.

So misperception is not the sole issue. Only some parents who do know their child is overweight are troubled by it (Eckstein et al. 2006). Those that are concerned are more likely to adjust their child's diet, limit screen time, and encourage exercise (Moore, Harris, and Bradlyn 2012). Studying these parents could identify motivational triggers for remediation. In this regard, 'readiness to change' research should be useful (Rhee, McEachern and Jelalian 2014).

Parents' Knowledge and Beliefs about Healthy Households. Parents' perceptions and motivations may not be sufficient, as successful weight management also depends on their knowledge of nutrition, fitness and health. Research has focused on nutrition, so much less is known about parents' understanding of physical fitness. Nutrition studies show that children of knowledgeable parents have healthier foods at home, consume more fruits and vegetables, as well as eat less fat and fast food (Campbell et al. 2013; Contento et al. 1993; Tarabashkina, Quester and Crouch 2016). They are also better informed about what constitutes a good diet, and are less likely to be overweight (Slater et al. 2011). A majority of parents know basic nutrition and are aware of some diet related health problems, but gaps exist about healthy portion sizes and the nutritional quality of specific foods (Variyam 2001). Grasp of actual food intake is also key - longitudinal research found that when mothers were unaware of how often their 9-10 year olds were eating sweets, these children were more likely to be overweight 10 years later, a result independent of childhood BMI, gender, or parent education (Lissau, Breum and Sørensen 1993).

The implications of lack of knowledge are important. For example, in a study of low income families, parents of preschoolers had some awareness of problematic eating behaviors 
but failed to appreciate the risks of physical inactivity in their children (Hernandez et al. 2012). Fortunately, consumer research (Alba and Hutchinson 1987; Brucks 1985; Carlson et al. 2009) may be useful in both understanding the impacts of expertise and disentangling objective knowledge (what parents know) and subjective knowledge (what they think they know).

What do parents need to know beyond the basics of nutrition and exercise? Helping parents to understand how common heuristics affect their own food choices is a possibility, and consumer research offers many insights here. For example, Chandon and Wansink (2007) found that adult consumers underestimate calories in a restaurant with a health positioning (Subway), and suggest educational interventions to combat such tendencies. These could be used by parents to modify their own behavior, and to educate their children when eating out. Similarly in the perceptual sphere, individuals consuming large sizes labeled as "small" may not realize they are eating too much-'guiltless gluttony' in the authors' parlance (Aydinoglu and Krishna 2011). This effect is moderated by nutrition consciousness and cognitive load (which may be a common problem for busy mothers). Parallel concerns pertain to packaging limiting caloric intake (e.g., '100 Calorie Pack') as these can yield higher intake due to lapses in consumers' self-control (Scott et al. 2008). As parents both act on and transmit what they know, helping them to recognize and resist such biases is an important area for consumer research extensions.

Even if a parent has nutrition knowledge, it must be filtered through beliefs about raising a healthy child and the challenges faced in doing so. In a review of twenty-one qualitative studies, Pocock et al. (2010) found that parents do register positive beliefs, but they also report many barriers to success such as time constraints, feeling undermined by other family members, dealing with children's preferences, and the advertising of unhealthy foods. This parallels a Harvard Public Health survey (2013) finding that while almost all parents (95\%) agree it is 
important that their children eat healthfully, $44 \%$ say it is difficult to ensure that they do. To translate intention into action, parents need both strategies and confidence in their ability to prevent obesity. Parenting self-efficacy is a robust predictor of parental competence and child adjustment across domains (Jones and Prinz 2005). However, very few studies have focused on diet related outcomes. Those that have find that maternal parenting self-efficacy predicts infant weight status (Anzman-Frasca et al. 2013), and that enhancing parent's self-efficacy can lead to greater vegetable intake in children (Gholami et al. 2015). Consumer researchers have used the self-efficacy concept to understand adult behaviors (Park and John 2014), and might wish to extend this thinking to how parents' self-efficacy perceptions relate to better diet and exercise profiles for their children.

As noted near the bottom of figure 4, attention might also be given to a parent's personal concerns about weight, eating, and exercise, and how these impact their children. Parental sensitivity about weight can color a child's experience, as suggested here:

“There's a kind of fear, a fear of obesity. But I don't talk about it a lot because my mother's side is obese and there's... such a negative spin on that."(St. James et al. 2011, 639).

One element underlying such sensitivity is awareness that an overweight appearance can lead to negative reactions by others, consciously or not. Consumer researchers have documented such impacts on both the self-image of, and amount of food consumed by, adults observing others who are overweight (Campbell and Mohr 2011; McFerran et al. 2010). Children may internalize such reactions, as peers are powerful influences on adolescents' consumption of both healthy and unhealthy foods (Mackey and La Greca 2007).

Beyond parents' personal concerns, their own approach to eating can have significant effects on the child. For example, EAH is more common in children with a parent who is a 
disinhibited eater, is overweight, or who adopts restrictive practices about food (Francis et al. 2007). Mothers' binging also leads to children's binge eating and loss of control (Zocca et al. 2011). At the other end of the spectrum, overweight mothers are more likely to encourage their adolescents to diet, perhaps due to their own struggles with weight (Fulkerson et al. 2002). This brings us to the broad realm of parent-child interactions, Sector IV in figure 1, depicted in the center of our Family Consumer Socialization Framework.

\section{FOCUSING ON PARENT-CHILD INTERACTIONS}

Although the approaches parents take to socializing their children are deeply rooted in the social, economic and cultural fabric of their lives, ultimately, they have the capacity to decide how they wish to raise their children. But how do they go about it, and with what impacts on obesity? Much attention in childhood obesity research has been given to the effects of specific parenting actions. Consider, for example, that a four year-old who lives in a household in which she regularly eats family meals, obtains adequate sleep, and has limited screen time $(<2$ hours per weekday), has a $40 \%$ lower probability of obesity than a child whose home provides none of these (Anderson and Whitaker 2010). And a recent field intervention suggests that these changes can be implemented and will reduce BMI (Haines et al. 2013).

Foundational Property IV: Parenting Practices Serve to Either Foster or Protect Against Overweight. 
are primarily responsible for establishing the emotional climate and patterning of behavior within the household. Years of family socialization research have shown that a child's internalization of desired behaviors is fostered by three parenting qualities - autonomy support (gentle behavioral control, providing appropriate choices), clear expectations, and warm personal involvement (Grusec and Davidow 2007). When these are not in place, problems may develop. For example, low levels of parental warmth and intimacy lead to greater weight concerns among teen girls, the onset of early dieting, and problems with dieting successfully (May et al. 2006). However, 'family connectedness' seems to help, as overweight teens from such homes report fewer health compromising behaviors and less psychosocial distress (Mellin et al. 2002).

It is the negative messages about weight and body shape parents convey that lead to children's disturbed eating (May et al. 2006). Children are very sensitive to parents' views about their weight and physical attractiveness: at a relatively young age (9-11) they predict their parents' weight appraisals, and being seen as too fat (or too thin, for boys) is tied to lower selfesteem (Neumark-Sztainer et al. 2010; Pierce and Wardle 1993). But are children's perceptions of their parents' views accurate? Perhaps not: one study found that daughters underestimate how attractive their parents describe them to be (Geller et al. 2003), but more evidence is needed.

Further, while obesity studies tend to focus on negative impacts, parental signals can also lead to positive outcomes. For example, parental encouragement can lead to increases in a child's physical activity by first raising his or her perceptions of self-efficacy or competence (Craggs et al. 2011). As indicated in figure 5, additional study of how parents can support a child's positive self-image through diet and physical activity is needed, as is research on family relationships and emotional dimensions related to child weight (e.g., Frankel et al. 2012). 
Insert figure 5 about here

'Parental Style' Sets the Household's Emotional Climate. One useful theoretical framework for examining household climate is parental style. This framework focuses on the attitudes, values and behaviors that typify a parent's interactions with a child, setting the general context for child rearing (Darling and Steinberg 1993). Derived from Baumrind (1971), two dimensions, parental warmth and control, are crossed to define four distinct styles: Authoritative (high warmth, high control); Indulgent/permissive (high warmth, low control); Authoritarian (low warmth, high control); and Neglectful (low warmth, low control). It has been used in many fields including consumer research (Carlson and Grossbart 1988).

Authoritativeness (emotional support, expectations for self-control, and appropriate granting of autonomy) helps to build competent self-regulation, and children of authoritative mothers are indeed at lower risk for overweight (Darling and Steinberg 1993). Conversely, children of authoritarian mothers (who are not as sensitive to emotional needs) are at greater risk for overweight, as are children of indulgent and neglectful mothers, who provide little direction (Rhee et al. 2006; Topham et al. 2011). In these cases, children may lack a sense of emotional security, either because the consequences for not meeting parents' standards are too harsh, or because parents haven't set needed limits.

However, the same parental style impacts do not seem to hold for physical activity, though evidence here is less clear. Some studies find that it is children of indulgent/permissive mothers who engage in more physical activity, likely being assisted by enrollment in sports and ready 
transportation from family members (Hennessy et al. 2010; Jago et al. 2011). Others find daughters of authoritarian parents more likely to participate in organized sports, perhaps related to the parents' proclivity to place greater controls on their children (Saunders et al. 2012).

Given these apparent inconsistencies, our second major topic in figure 5 highlights the need for more research on parental styles and practices that foster or undermine children's internalization of healthy behaviors. The parental style framework has stimulated much debate in the obesity literature, over the breadth of the concept as well as inconsistencies in terminology and metrics (Blissett 2011; Vaughn et al. 2013). Some researchers ask whether the framework explains sufficient variability (De Bourdeaudhuij et al. 2009; Vereecken, Rovner, and Maes 2010). And research is needed to lend insight into underlying mechanisms. Both permissive and neglecting parenting styles are linked to obesity (Rhee et al. 2006), but why are these children not learning to self-regulate? The concept of 'parent feeding style' has been suggested as a way to add needed domain specificity (Hughes et al. 2005). Recent research here is informative: it finds that parents who use an 'indulgent' feeding style have children who enjoy food more, but are less responsive to satiety cues, and have higher BMIs, thus directly linking parent feeding style to a child's low self-control (Frankel et al. 2014).

Parenting Practices: Restricting Children's Consumption of Unhealthy Foods. We now turn to consideration of more specific actions undertaken by parents. Narrower than parental style, parenting practices are localized tactics used to monitor and control what, how much and when children eat. A key dietary issue for parents involves how to limit a child's intake of unhealthy foods (Ventura and Birch 2008). Common means of restriction include keeping foods high in sugar, fat or sodium out of reach, limiting quantities, or permitting them only after 'good 
foods' have been consumed. While these reduce intake in the short run, do they bring long term benefit or harm?

Some researchers suggest harm, because restrictions impair a child's self-regulation (Birch, Fisher and Davison 2003; Rollins et al. 2014). In EAH studies, for example, children (ages 3-6, normal weight) had free or restricted access to equally liked snacks. More positive comments were made about the restricted snack (visible but inaccessible) and, with restrictions lifted, children ate more of it (Fisher and Birch 1999). Such impacts extend beyond the food of interest, as restriction of one desired food (chocolate) can increase children's desire for other highly sweetened foods (Ogden et al. 2013). And the effects on children are not only immediate: a high level of restriction imposed at age five predicts girls' EAH at ages seven and nine (Birch et al. 2003). Children of certain temperaments, especially those with lower inhibitory control, are particularly vulnerable (Anzman and Birch 2009; Rollins et al 2014).

If weight outcomes are considered, however, evidence is less clear. Some studies find that restriction promotes overweight (Cardel et al. 2012), but others show no effect or even a safeguarding impact (Carnell and Wardle 2007; Gubbels et al. 2009). For example, Campbell et al. (2010) found parent restriction imposed at ages 5-6 protected against obesity three years later, but no effect of restriction at ages 10-12 on subsequent weight status, perhaps due to adolescents' greater access to foods outside of the home.

It is important to note that cause and effect is an underlying issue here, as parents might begin to impose restrictions because a child shows signs of poor self-regulation. In that case, restriction is more the result of maternal concern than a cause of weight gain (Blissett 2011; Ventura and Birch 2008; Webber et al. 2010). Thus the impacts of food restriction are still being debated, and could be addressed by consumer researchers. If so, there is a need to clarify exactly 
how restriction has been defined and applied across studies (Faith et al. 2004). Sampling may also be a factor. Hispanic mothers are more likely to use restrictions than either White or African American mothers (Cardel et al. 2012), thus highlighting a need for substantive studies to understand ethnic differences (Cross et al. 2014). Moreover, little research yet reflects the nuances of actual use within parent child interactions: impacts of restriction may well differ if imposed warmly and supportively (an authoritative style) rather than unilaterally (Blisset 2011; Carnell and Wardle 2007). More broadly, there is a need to integrate the distinct research streams of parenting style, feeding style and parenting control practices, a call echoing a major research priority set by an expert committee of the American Heart Association (Faith et al. 2012).

Parenting Practices: Encouraging Children to Eat Healthy Foods. In contrast to the restriction of unhealthy foods is the common practice of encouraging children to eat healthier options. The risk here is that by focusing a child's attention on external cues ('it's good for you'), a parent risks undermining a child's use of his or her own physiological cues signaling hunger or satiety (Birch 1998). Indeed, a negative relationship between parental pressure and children's intake of fruits and vegetables has been reported in some surveys, though the causal direction isn't as clear (Wardle, Carnell and Cooke 2005). Experimental evidence shows, however, that preschoolers pressured to eat a certain soup not only made more negative comments about it, but ate less, and had reduced preference for it over time (Galloway et al. 2006). Relatedly, when food is used as a reward ('no dessert until you finish your vegetables'), children eat more vegetables on that occasion, but preference for them declines (Birch, Marlin and Rotter 1984). Young adults' accounts of such forced consumption episodes in childhood indicate that some of these foods are avoided even years later (Batsell et al. 2002). 
A Useful Distinction: Overt versus Covert Parental Controls. Both restriction and pressure bring risks due to children reacting negatively, consciously or not, to constraints placed on their desires. Can parents mitigate these reactions? Ogden, Reynolds and Smith (2006) suggest a distinction be made between overt and covert mechanisms. Both restriction and pressure to eat are overt mechanisms readily perceived by a child. In contrast, covert mechanisms (not having certain foods in the home, avoiding restaurants with unhealthy foods) can go largely undetected, thus avoiding a child's reactance. Research has found more use of covert controls by thinner parents, resulting in reduced intake of unhealthy snacks by their children (Brown et al. 2008; Ogden et al. 2006). Use of overt controls, on the other hand, was unrelated to parents' weight, but assisted in increased consumption of healthy snacks. Thus it appears both forms of control can be effective, but in different ways. This is intriguing, with much still to be learned.

There is a need for more inclusive study of approaches parents can and do use to control their children's weight, and the overt versus covert distinction can be a useful starting point. Building on successes in adult weight loss programs (e.g., rewards, recognitions) may also have potential. For example, Moisio and Beruchashvili's (2010) study of Weight Watchers might assist in developing innovative parenting methods for testing. Beyond the approaches themselves, how do parents choose control strategies? The obesity literature has generally underplayed children's agency - how children's desires impact parents' decisions. However, consumer researchers have long studied children's influence and could extend this to parents' choice of dietary control strategies as a function of a child's age, gender, or temperament. Research on children's responses to specific parent control strategies is also needed, and a strong candidate in this regard is reactance theory. 
Encouraging Adolescents to Diet. Research on parental controls has focused on younger children, as it can be difficult to directly limit the behavior of an older, more independent child. One way to exert influence is to encourage an older overweight child to diet, but findings here are paradoxical. Healthy dieting is clearly beneficial, but evidence instead shows that teen dieting leads to weight gain, as a result of such unhealthy behaviors as skipping breakfast, binge eating or excessive fasting (Neumark-Sztainer et al. 2007). Parental encouragement to diet does increase weight loss attempts, and is linked to BMI reductions, but as many as half the children who are encouraged to diet are not overweight (Fulkerson et al. 2002). Presumably this is due to parents' own struggles and resultant weight sensitivity, leading to heightened vigilance with their children. However, being counseled to lose weight by parents can negatively affect a teen's selfperceptions. Both girls and boys who are urged to diet express more weight concerns, greater body dissatisfaction, and beliefs that being thin would increase their happiness, success, and social acceptance (Benedikt, Wertheim and Love 1998; Francis and Birch 2005). They are also more likely to binge eat, and engage in other negative weight control behaviors (Fulkerson, et al. 2002). Thus, interacting with an overweight child about dieting is a complex and sensitive family challenge.

Creating a Healthy Home Environment

Scheduling Family Meals. Our third major research topic in figure 5 begins with family meals, a mainstay of 'family time' in many households (Epp and Price 2012) and a positive 
cornerstone in forestalling weight problems. Belk's (2010) treatise on 'sharing' casts the family meal as a bonding ritual, a symbol of love, nurturance, health and happiness. Historically an American family ritual, the trend is away from family meals, with greater reliance on eating separately, convenience foods and restaurants. This is unfortunate, as family meals are a straightforward means of influencing a child's diet.

Much evidence shows that the socializing effects of family meals do reduce obesity risk for children and teens (Berge et al. 2014; Hammons and Fiese 2011). Families with normal weight children have more positive interaction during meals and view mealtimes as more essential than do those with overweight children (Fiese, Hammons and Grigsby-Toussaint 2012). Family meals also coincide with fewer unhealthy weight control behaviors, particularly among teen girls, as well as safer practices in health domains such as smoking and alcohol use (Eisenberg et al. 2004; Neumark-Sztainer et al. 2004). Eating frequent family meals is associated with better adolescent diets and reduced soft drink use (Neumark-Sztainer et al. 2003; Videon and Manning 2003). And there are positive long term consequences. Regular family meals in early adolescence tie to healthy diets five years later, and family meals during high school are associated with better diets into young adulthood (Burgess-Champoux et al. 2009; Larson et al. 2007). Even when a parent is overweight, positive family meal practices shield children to some extent (Lytle et al. 2011).

Perceptual Food Management. Parents also decide on portion sizes, foods served at meals, and their own eating behaviors, all of which can affect a child's weight. Parents create food environments that promote healthy habits or not, and are guided by perceptual processes of which they may not be fully aware. For example, a study of family dinners observed parents serving their preschoolers similar sized portions to what they served themselves (Johnson et al. 
2014). This is of concern because children do eat more when given portions that are larger than age appropriate (Fisher and Kral 2008).

It is unlikely that parents intentionally overfeed their children, so beyond educating them about child portions, what might be done? Useful insights emerge from consumer research (Finkelstein and Fishbach 2010; Irmack, Vallen and Robinson, 2011). Features such as the perceived variety of a food assortment (Kahn and Wansink 2004), and the size of plates, serving bowls, and/or utensils can all impact the quantity that will be consumed. For example, overweight teens consume less juice when pouring into a tall, thin glass relative to a short, wide glass, despite having estimated pouring more (Wansink and Van Ittersum 2003). Consumer research on the 'Delbouef Illusion' also shows that the size of dinner plates can lead to serving too much food (large) or less food (small), with plate color moderating impacts (Van Ittersum and Wansink 2012). As education reduces but does not eliminate this bias, the authors suggest people simply be encouraged to use smaller plates (readers interested in portion size will find recent reviews by Birch, Savage, and Fisher 2015 and Zlatevska, Dubelaar, and Holden 2014 to be instructive). Preliminary findings from a related National Institutes of Health (NIH) trial with five families of 8-12 year olds are encouraging: the combination of dinnerware substitution, making unhealthy food inconveniently located, and limiting children's TV viewing were effective in reducing food intake (Robinson and Matheson 2012).

Perceptual research can also be helpful in promoting a healthy diet. If past lab studies generalize, parents may be able to covertly increase consumption of healthy foods by adjusting fruit and vegetable portions while reducing or holding entrée size constant (Kral et al. 2010; Mathias et al. 2012; Savage et al. 2012). Other covert possibilities include serving vegetables at a meal, adding pureed vegetables to entrees, or substituting ingredients to reduce calories -- these 
can be effective because both adults and children tend to eat the same weight of food even when calories have been reduced (Leahy et al. 2008; Spill et al. 2010, 2011).

In summary, changes in dinnerware, food assortment, ingredients, and portion size all represent 'covert parenting' methods to assist in weight control. And, if internalized by children as norms, such changes could benefit them throughout life. Additional research on families' effective meal management (both in the home and outside it) would be valuable.

Food Purchasing. The food purchase decisions made by a household lay the groundwork for creating a healthy home environment. In the short run, these form the basis of a child's diet: in the longer term the child is socialized into his or her own food buying habits and preferences that will guide health and weight status. This area offers many consumer research opportunities.

As one of the routines that shape family life, grocery shopping is a central household activity. Children's desires play a key role, either when in the store exerting their influence directly, or when their desires are taken into account as a parent shops alone. As they mature, children develop increasingly sophisticated influence and negotiation strategies in family decision making (John 1999). Both observational studies in grocery stores and parent accounts indicate that a majority of children make product requests or demands, and that parents accede to somewhere between 45-66\% of these (Atkin 1978; Galst and White 1976; Gaumer and Arnone 2010; Isler, Popper and Ward 1987). What do they want? Half of children's requests are for snacks or sweets, and a majority of those that are granted are for unhealthy items (O'Dougherty, Story and Stang 2006).

Although parents report that they want to choose nutritious foods for their families, practical matters such as needing to move through a store quickly, appease children, and find 
attractive price points all intervene. This can result in greater reliance on decision heuristics than nutrition labels or other detailed data (Maubach Hoek and McCreanor 2009). Further problems arise for low income families: children's requests in tandem with limited resources can make it difficult to purchase healthy foods while also stocking needed quantities and household assortments (Zachary et al. 2013). So these parents may be especially reluctant to buy foods their children might not eat, thus limiting trial of healthier options (Wingert et al. 2014).

Prices are significant factors in shaping food purchase decisions. Supermarket scanner and experimental studies reveal consumers' demand sensitivity for healthy foods is greater for a price increase than a decrease, but the opposite is true for unhealthy foods (Talukdar and Lindsey 2013). This suggests that consumers are more responsive to price promotions when offered on unhealthy foods than when more nutritious options are placed on deal. Also, it may be that some parents (and their children) perceive the costs of certain healthy foods as too high, and avoid them for this reason. However, according to both the USDA and the Center for the Science in the Public Interest (CSPI) fruits and vegetables are less costly snacks and side dishes than processed foods (Mushi-Brunt, Haire-Joshu and Elliott 2007).

Future research on children's roles in, and learning from, food purchasing would be useful. Although close to half of adolescents report that they help in shopping for groceries (even higher among low income teens), food related research has been focused on younger children (Larson et al. 2006). Little is known about the changing dynamics of parent child shopping interactions as children mature. Understanding more about how parents educate their maturing children about healthy food shopping and spending decisions is thus a future research topic listed in figure 5.

Other research findings can be useful in helping parents be more aware of personal shopping proclivities, and thus what they may be passing onto their children. For example, one 
early consumer study revealed that obese shoppers increased their total grocery spending after eating in-store samples, while those who were not overweight did not: this difference was attributed to heightened sensitivity to food cues among the obese (Steinberg and Yalch 1978). Research also suggests that those trying to restrain their eating will benefit from planning their purchases before shopping. In Stilley, Inman and Wakefield's (2010) study of mental budgeting (planned items and unplanned 'slack'), impulsive consumers tended to respond to visceral urges, using slack to buy more unhealthy items. Relatedly, paying with credit cards can lead to more unhealthy food purchases, presumably due to impulsivity and the 'lack of pain' compared to cash payments (Thomas, Desai and Seenivasan 2011). This is an exciting area for future study given evidence that choice heuristics are transmitted from parents to children (Moore and Lutz 1988).

Parents' Mediation of Marketing Influence Attempts. Many authors have suggested that the current 'obesogenic' environment promotes excessive food consumption, and that marketing is a key contributor (McGinnis et al. 2006). According to the Federal Trade Commission (2012), major food marketers are spending $\$ 1.8$ billion annually to promote their products directly to children and teens (with $\$ 9.65$ billion in total promotional spending). What is the marketing ecosystem encouraging for diet and physical activity, and how does it affect children? The base of research on advertising to children has much to contribute to this avenue of investigation (e.g., Brucks et al. 1988; Connell et al. 2014; John 1999; Moore and Lutz 2000), but marketing stimuli are also broad and expanding apace with new media (Moore and Rideout 2007). How can parents help their children learn to deal with the current food environment? Are parents less capable referees due to their own biases based on childhood marketing memories (Connell et al. 2014)? Externally, restaurants hold great potential for help or harm, especially with food portions 
having grown considerably. Grier et al. (2007) report that ethnic minority parents exposed to extensive fast food promotion in their neighborhoods tend to view eating these foods as normative, leading to greater consumption of them by their children (ages 2-12). In contrast, childhood obesity has been a frequent recent topic in the popular press: has this stimulated any changes in parents' efforts to mediate marketers' influence attempts?

Parenting and Children's Physical Activity. The vast majority of childhood obesity studies have focused on food intake, but energy expenditure also offers research opportunities. American children's sedentary activity has increased: use of computers, video games, TV, music, and movies now account for over seven and a half hours of their day (Rideout, Foehr and Roberts 2010). They walk less, travel in cars, and take fewer physical education classes (Anderson and Butcher 2006).

Benefits from a child's physical activity include weight control, health maintenance, and positive emotional effects on body image (Monteiro Gaspar et al. 2011). As noted earlier, most U.S. children do not meet activity guidelines and there are precipitous drops in physical activity among today's adolescents, especially girls (Dishman et al. 2009; Eaton et al. 2010; Nader et al. 2008). However, teens on sports teams or who walk or bike to school have much lower obesity rates. This is a worthwhile option for parents to encourage, as it has been estimated that obesity rates would drop by more than $20 \%$ if all teens participated in these activities (Drake et al. 2012).

The neighboring built environment is a key influence on children's physical activity (Sallis and Glanz 2006). Traffic density/speed, crime, and deprivation suppress physical activity, while safe, accessible recreation facilities raise levels (Davison and Lawson 2006). Not surprisingly, disparities by SES and ethnicity exist in participation opportunities (Eaton et al. 2010; Whitt- 
Glover et al. 2009). Teens from lower SES groups are less likely to play team sports or attend schools that require physical education (Johnston, Delva and O'Malley 2007). And there is some evidence of ethnic differences in benefits accrued from exercise. Higher physical activity at age 12 lowers obesity risk at age 14 for White girls, but not for Black girls: metabolic rates at rest and during exercise may underpin this effect (Lee and Arslanian 2008; White and Jago 2012). Public health officials have strived to develop effective physical activity strategies for many years. However, a recent meta-analysis of 30 programs found: “...only a small effect (...4 minutes more walking or running per day) on children's overall activity levels” (Metcalf, Henley, and Wilkin 2012, 16). Thus the need for parent involvement seems even more central. Why would parents whose children need more physical activity not be encouraging it? One answer, parallel to parental misperceptions, is that many seem to be generally unaware of their children's actual activity levels, and satisfied that there is no problem. For example, $80 \%$ of parents of 'inactive' children, based on actual accelerometer data, reported their child was sufficiently active (Corder et al. 2010). In a second study parents of high risk 5-7 year olds expressed little concern about their activity levels, believing their children were naturally 'active enough' (Lopez-Dicastillo, Grande and Callery 2010). Although exploratory, these studies raise questions about how parents can become motivated to increase their child's energy expenditure.

If a parent is inspired, what options exist? Pugliese and Tinsley (2007) identify three primary strategies: parental modeling (child learns by observing parents exercise or by joining in), parental encouragement, and assisting with child participation (transport, fee payment). Their meta-analysis revealed moderate positive effects of each strategy on physical activity. With respect to parental modeling, gains seem to be occurring: the number of U.S. children who report being physically active with their parents rose from 16\% in 2003 to $31 \%$ in 2010 (Moag- 
Stahlberg 2011). With regard to parental encouragement, multiple studies show success from improving a child's perceived competence in the activity (Craggs et al. 2011; Dishman et al. 2009; Dowda et al. 2007). Predictive models of children's physical activity that include mediating variables are now needed, these to be used in planning family-based intervention programs (O’Connor, Jago and Baranowski 2009; Pugliese and Tinsley 2007).

Extensions across Domains. The final set of entries in figure 5 highlights research opportunities that span the sectors of our consumer socialization framework. First, as childhood covers an extended period with great changes, it is difficult to generalize across time. At present, age differences are implicitly recognized in the choice of study samples (e.g., family meals with teens, parental controls with young children), but there is a real need for systematic analysis of parenting practices across a child's development and their influence on weight outcomes.

The second entry recognizes parental modeling, a topic that impinges on disinhibited eating, emotions and food, self-control depletion, portion sizes, grocery shopping, healthful eating, physical activity and elsewhere. Given its key role in child learning, there is a need to better understand how parents serve as role models, intentionally and not, and the extent to which unintended consequences, either positive or negative, tend to occur.

A third set of research opportunities emanates from families themselves, in that different individuals can be socializing agents for a child. Obesity research has focused on mothers, with impacts of fathers, siblings, grandparents and other caregivers not much understood. Beyond the influence of one of these family members, their interactions also provide interesting questions to pursue. For example, how often do mothers and fathers disagree on dietary matters, and with what results? Psychologists have studied parenting similarities and differences (Holden and 
Miller 1999), but not in the obesity context. When grandparents are close, what impacts do they have on the child's socialization for diet and exercise? This is not a minor matter: over seven million U.S. children are now living in households with their grandparents (Ellis and Simmons 2014).

\section{INTERGENERATIONAL TRANSFER}

We now turn to the rightmost sector of our family consumer socialization framework (figure 1) to discuss research needs from a somewhat distinct research perspective. Here outputs from the combination of genetics and years of episodic activities are investigated. Focus is on exactly what the child takes away from the family that impacts weight status.

Foundational Property V: The Roots and Sustaining Forces Supporting Childhood Obesity are Intergenerational in Nature.

Rooted in socialization theory, intergenerational (IG) influences is a burgeoning research area focused on within family transmission of information, resources and preferences from one generation to the next. Research has shown IG influences at work in many spheres, such as achievement orientation, religious values, political affiliation, and gender and racial attitudes (e.g., Beck and Jennings 1991; Whitbeck and Gecas 1988). Of special interest is evidence indicating that 'explanatory style' (optimistic or pessimistic) is transferred intergenerationally from mothers to their children (Seligman 2006). This is the lens or 'habit of thought' that we use to cope with events in our lives, and can impact our happiness, productivity and physical health.

Research in nutrition and public health has revealed a range of IG impacts. A significant, modest relationship exists for parents' and children's participation in vigorous exercise, with an 
even stronger relationship for sedentary activities (Fogelholm et al. 1999). IG links have been found for a proclivity to overeat, approaches to weight control, and foods children come to prefer and avoid. Parent child similarities exist for both healthy and unhealthy foods, including fat, soft drinks, snacks, milk, fruits and vegetables (Fisher et al. 2004; Hanson et al. 2005; Raynor et al. 2011; Watts et al. 2014). Ethnic differences have been little examined, but IG dietary influence appears highest among Hispanics (Beydoun and Wang 2009), with food availability data showing low income Hispanic children having greater access to fruits and vegetables than low income African American children (Skala et al. 2012). Such IG influences are key, as learned preferences for fruits or vegetables can protect against obesity (Savage et al. 2007).

IG influence also extends to eating styles and ideas about dieting, some health promoting and others not. Dietary self-efficacy (e.g., confidence in avoiding red meat, not adding salt or drinking nonfat milk) tends to be shared by family members (Rimal 2003). Food 'neophobia' is also an IG phenomenon: parents reluctant to try new foods have children who tend to be 'picky eaters' (Falciglia et al. 2004). And IG influences lead to 'dietary disinhibition,' which is strongly linked to obesity (Morrison et al. 2013; Zocca et al. 2011). Disinhibited eaters find it hard to resist temptation, even when not hungry, and also eat when distressed. This tendency surfaces at a young age. In the Framingham Children's Study, at baseline (ages 3-5) there were no differences in children's adiposity, but over the next six years body fat increased linearly with higher parental disinhibition, a pattern exacerbated if both parents were disinhibited eaters (Hood et al. 2000).

IG research exploring adolescents' proclivity to diet is mixed, appearing to depend on the type of dieting (Snoek et al. 2009). For example, some studies find IG impacts between mothers and teenage daughters only for extreme dieting behaviors such as fasting, skipped meals, or crash 
diets (Benedikt et al. 1998).This is consistent with earlier studies showing links between mothers' and daughters' disordered eating patterns (Pike and Rodin 1991).

\section{Carrying Forward into Adulthood}

The foregoing research reflects on children currently living in the home, and thus restricted to some extent to the food and exercise options available there. But what happens when they mature and move away? IG impacts are likely to weaken at this time, as young adults encounter new opportunities and influences, but some IG impacts are well internalized and will persist in adulthood (Prichard et al. 2012). Consumer researchers have studied this issue, though not with respect to obesity per se (Childers and Rao 1992; Cotte and Wood 2004; Moore et al. 2002). For example, Moore et al. (2002) report a strong IG preference carryover for 23 of 24 food and household products in parallel surveys of mothers and their young adult daughters who were living away from home. The addition of the IG relationship produced a $63 \%$ predictive gain over randomly paired mothers and daughters. In a second study these authors used depth interviews to extend theory on IG persistence. They found that special foods and rituals, family lifestyles (e.g., vegan), shopping styles (e.g., lists), social influences, and marketing actions are all factors serving to sustain, or to disrupt, the family IG bond (Moore et al. 2002). This conceptualization points to opportunities for building greater understanding of the dynamic aspects of IG.

Listed in figure 6 are three IG research topics that we view as especially important. First, 'within-family transmission' would use traditional IG research methods to study issues specific to childhood obesity. Which elements of diet, physical activity, and weight management are 
being strongly transmitted, and with what effects? Much remains to be learned in this area (Wang et al. 2011). For example, consumer researchers have studied adults' choice heuristics (e.g., "guiltless gluttony," overeating with 100-calorie packs): are these biases being transferred to children? Are weight-related stereotypes held by some parents, such as "Fatness indicates ... deficiency of character" (St. James et al. 2011, 638) also being transmitted across generations within families? What is the nature of ethnic differences with regard to IG influences, and how might findings be used in developing tailored intervention programs?

Insert figure 6 about here

"The Dynamics of IG" section in figure 6 shifts focus to processes involved in IG transfers. Are parents inadvertently modeling unhealthy eating behaviors and thereby fostering excess weight gain in their children? For example, mothers who are self-proclaimed emotional eaters tend to use emotional feeding, such as giving a child food when he or she is upset (Wardle et al. 2002). Positive modeling impacts are also possible. When a mother participates in a weight loss program, what do children take away from this exposure? How does the home food environment change, and is the child's weight locus of control altered?

Studies of intergenerational dynamics should also consider reverse IG, or the role of the child as the influencer. With respect to food and physical activity, in what domains does reverse IG occur? Many obesity interventions are now undertaken in school-based programs, which may aim to stimulate reverse IG. As a child acquires new information at school, is that learning transferred to the home environment, and to what effect on other family members? At what stages of development is reverse IG most consequential? How does reverse IG operate when a 
young adult returns home with new dietary experiences and preferences? Given a child's potential to influence family outcomes, dyadic or triadic measures may be best for this research, as findings in both obesity research (Taylor et al. 2011) and consumer research show adolescents tend to overstate their influence within the family (Beatty and Talpade 1994).

Families also differ in the strength of their IG bonds, a result that has not yet been much studied. Why are some families' IG connections stronger than others? Factors to consider might include family structure and stability, character of parent-child relationships, the extent and types of shared versus independent activity, and the emotional tenor of the home. And temporal dimensions of IG are also of interest. Are today's parents drawing from what they learned as children from their parents (who may be present or nearby to assist in raising grandchildren)?

Finally, the third entry in figure 6, potentials for positive IG, recognizes that much childhood obesity research has focused on negative outcomes and their causes. IG research also affords a chance to study families who have been successful in managing their children's weight, which could provide useful lessons for other families now facing this problem.

\section{CONCLUSION}

Project Goals and Conceptual Foundations

Childhood obesity is an international problem threatening the futures of millions of people in terms of physical health concerns, needed medical care, and emotional suffering. Present trends suggest that the youth of today could lead shorter and less healthy lives than their parents-a shocking testament to the dangers of this epidemic. Calls for assistance have arisen 
from the highest levels of societies.

In our own discussions with child advocates, public policymakers, and concerned marketers, the question of marketing's culpability in the crisis is central, but is almost always quickly countered by the challenge: "Isn't this really the responsibility of parents, though?" And, while it is true that a family's myriad consumption choices of food and physical activity are focal contributors, neither the marketing nor the consumer research literatures have much addressed this dimension of the problem. Thus arose the impetus for our extended discovery project into this complex phenomenon as investigated across an expanse of fields (including genetics, pediatric medicine, developmental psychology, nutrition, physiology, family studies, public health, and consumer research), as well as an assessment of what is known and what is still to be learned. Our goal for this article is that JCR readers will both understand more about the nature of the family's role in the problem of childhood obesity, and perceive new possibilities for needed consumer research undertakings.

Most fundamentally, the project is grounded in our "Family Consumer Socialization Framework" (figure 1), which reflects both a child's developmental progression (toward or away from obesity), as well as the roles played by the family in fostering weight problems or protecting children from them. This framework is distinct from existing consumer socialization models not only in its domain specificity, but also in its in-depth treatment of the family's impacts arising through three interdependent sectors, the child, the family, and parent-child interactions. Inclusion of all three sectors in the analysis allows us to surface the rich set of issues that emerge when multiple perspectives are taken. We believe this approach to be particularly appropriate when relational phenomena are being investigated, as different levels of analysis (individual child, individual parent, parent-child dyad, family unit) can be accommodated within 
this framework.

In her classic overview of the field, John (1999) characterizes consumer socialization research as centered largely on the child, with age as the dominant focus and emphasis on understanding age related shifts in information processing capacity, learning and knowledge. Factors beyond a child's age also need careful consideration, however, as “... important developments in consumer socialization do not emerge in a vacuum, but take place in a social context including the family, peers, mass media and marketing institutions" (John 1999, 188). Although there have been studies that include one or more of these variables "we continue to have significant gaps in our conceptualization and understanding of exactly what role social environment and experiences play in consumer socialization" (John 1999, 205).

Our framework with its focus on the family addresses this gap within the obesity domain. As we have pointed out, the obesity literature's relative lack of attention to children's evolving cognitive capacities is a shortcoming, and consumer researchers can bring this perspective to the study of childhood obesity. Emphasis on the child sector of our framework highlights developmental considerations, learning and self-regulation, and thus aligns with traditional consumer socialization research. However, the need to also consider physical maturation and weight status poses an additional set of challenges in this sector.

Shifting focus to the family first highlights the significance of a child's physiological predispositions (genetic heritage and physical characteristics), reflecting that some children begin their lives with tendencies toward obesity. However, whether obesity is subsequently realized or avoided depends substantially on the socialization processes that follow. With respect to John's (1999) call, our focus on the family sector provides insight into the immediate social environment that children with different risk propensities experience, and also reveals how 
that environment may be shaped by key cultural and structural factors that situate families in society.

Direct attention to parent-child interactions in Sector IV then features the reciprocal and evolving nature of family communications, and can focus attention on individual dyads (e.g. mother-daughter) or other relational units within the household as well as the difficulties associated with managing weight control. Our framework also explicitly considers socialization's dynamic character to capture the developmental progressions that modify the household setting as well as the parents and children within it. Not only does the child mature and the family evolve over time, but the family's and child's recurring consumption practices (of both food intake and physical activity) serve to instill and ultimately internalize particular practices. These outcomes of the family socialization process are captured in our framework through the intergenerational transfers of weight related beliefs and behaviors that now reside deeply within, and guide the child's passage into adulthood.

To structure the analysis of our family consumer socialization framework, and bring it to focus on obesity research, we developed a second conceptual framework: the "Five Foundational Properties of Family Influences on Childhood Obesity." This was designed such that each property corresponds to a specific sector of our larger framework yet also offers a fundamental insight into the family's role in childhood obesity. Essentially, the five foundational properties help us to integrate what is known across disparate fields. Our investigations into each revealed many research opportunities: figures 3-6 present our findings, indicating gaps in knowledge about childhood obesity that might be bridged by new pathways from consumer researchers.

\section{Limitations}


While families are the nexus of the childhood obesity epidemic, they are not the only influences. Children are also subject to socializing influences from their larger ecosystems, including culture and subculture, school, church, peers, entertainment media, and marketing. The impacts of these influences evolve as children mature, which can challenge summary conclusions about a single agent. For example, as children move toward adolescence, peers become more influential in the choices of what foods to consume (both healthy and unhealthy) and the extent and nature of participation in physical activity. Reflecting this development, the bulk of research on peer influence focuses on children aged 10-18 (Badaly 2013). During late childhood and early adolescence (10-14 years) youth spend the majority of waking hours in the company of peers (Salvy et al. 2012), but are still based in their family household, with its routinized practices and preferences. This clearly increases potentials for tensions. Moreover, the direction and magnitude of peer effects on eating and activity behaviors can vary considerably depending on factors such as a child's weight status, whether peers are friends or strangers, and the social engagement and support received (see Badaly 2013 and Salvy et al. 2012 for comprehensive reviews of peer influence).

However, it is the case that parents (and the family unit) also operate within a larger ecosystem, and this creates many opportunities for parents to mediate the impacts of outside influences on their children. This is especially true when children are young and have less independent mobility outside the home. Even in adolescence, though, earlier internalization of healthful preferences and practices can be protective. And, parental actions such as fostering family meals not only help protect against obesity during the teen years, but create impacts that carry over into young adulthood (Burgess-Champoux et al. 2009; Larson et al. 2007). So parents 
are not irrelevant during adolescence. Direct comparative studies show that parents' impacts on diet and exercise are not supplanted by peers' but rather continue to play a role in adolescence and beyond (Baker, Little and Brownell 2003; Lau, Quadrel and Hartman 1990).

Marketing is of course another potential influence on obesity, one not dealt with in depth in this article. It should be noted, however, that isolating its impacts can be difficult. Marketing not only targets children directly, but also their parents, peers and subculture, sources who may then indirectly influence a child as well. Further, considerable research has been devoted to advertising's influence on children (e.g., Connell et al. 2014, Moore and Lutz 2000, Roedder 1981). A major National Academy of Sciences task force report concluded that there is strong evidence that exposure to food and beverage ads impact children's preferences and their food choices, reflective of an obesogenic environment. At the same time, however, it also concluded that marketing's impacts on childhood obesity are resistant to causal inference (McGinnis et al. 2006). And, while the bulk of research to date has focused on television advertising, the surge in new communication technologies cannot be ignored. There is great need for further investigation into marketing tools such as social media and 'advergaming' as well as parents' attempts to mediate these newer and perhaps unfamiliar influence sources (Moore and Rideout 2007, Owens et al. 2013). Finally, it is the case that marketing's efforts and offerings can also nudge both parents and children in either healthy or unhealthy directions. Altogether this is a very complex topic, worthy of its own sets of future investigations. The family consumer socialization framework in this article is amenable to studying interactions between the family and other socialization agents such as peers, the entertainment media, or marketing.

Into the Future 
Theoretical research to improve understanding of the family's consumption behavior with respect to childhood obesity is much needed, as we have shown. However, it is also the case that consumer researchers have rarely engaged in efforts to effectively modify or improve these practices, given the vagaries of the real world setting. We would underscore that research aimed at alleviating problems (through interventions) can be quite valuable, and we wish to encourage interested researchers to consider this route as well. The 'Transformative Consumer Research' (TCR) subfield is particularly well suited to pursuing such inquiry with its stated goal of improving consumer welfare. TCR scholarship welcomes diverse research paradigms and methods, and emphasizes the dissemination of findings to affected populations (Association for Consumer Research 2016). Many of the research needs identified above might lend themselves to the development and testing of interventions, such as those focused on parental perceptions and knowledge (see fig. 4 Foundational Property III) as well as steps parents might take to encourage healthy lifestyles (see fig. 5 Foundational Property IV).

For this type of research, it could be advantageous to join forces with scholars working in other disciplines who have not been trained in consumer research. For example, the capacity to bring together consumer researchers' understanding of marketing's influence on decision making, with the knowledge of parenting practices that obesity researchers have gleaned, could produce richer insights into the problems families face and how to resolve them (e.g., BraungartRieker et al. 2014; 2016). Comparisons of overt and covert parenting practices and/or implementation of EAH measurement may be particularly fruitful. Market segmentation, an area of expertise of our field, could also be brought to bear in new ways (looking beyond demographic descriptors) to identify parents and family units whose children are at greater risk 
for obesity. And, given the differential risk levels across children and families, intriguing possibilities exist for studies that examine potential gene-environment interactions, a burgeoning research area where the behavioral expertise of consumer researchers could be useful, and where little attention has been paid to the impacts of marketing activities.

Overall, this article provides a number of promising avenues for possible pursuit by our field. It is clear that consumer researchers have much potential to advance understanding, as well as to contribute to healthier consumption practices and brighter futures for children and their families. 


\section{REFERENCES}

Agras, W. S., Lawrence D. Hammer, Fiona McNicholas, and Helena C. Kraemer (2004), "Risk Factors for Childhood Overweight: A Prospective Study from Birth to 9.5 Years," Journal of Pediatrics, 145 (1), 20-5.

Alba, Joseph W., and J. Wesley Hutchinson (1987), "Dimensions of Consumer Expertise," Journal of Consumer Research, 13 (4), 411-54.

Amato, Paul R. (2005), "The Impact of Family Formation Change on the Cognitive, Social, and Emotional Well-Being of the Next Generation," Future of Children, 15 (2), 75-96.

Anderson, Patricia M., and Kristin F. Butcher (2006), "Childhood Obesity: Trends and Potential Causes," Future of Children, 16 (1), 19-45.

Anderson, Patricia M., Kristin F. Butcher, Hilary W. Hoynes, and Diane W. Schanzenbach (2014), "Beyond Income: What Else Predicts Very Low Food Security among Children?" Discussion Paper Series, DPP 2014-06, University of Kentucky, Lexington, KY 40506. Anderson, Sarah E., and Robert C. Whitaker (2010), "Household Routines and Obesity in US Preschool-Aged Children," Pediatrics, 125 (3), 420-8.

Andreasen, Alan R. (2006), Social Marketing in the 21st Century, Thousand Oaks, CA: Sage. Alan R. (1975), The Disadvantaged Consumer, NY: Free Press.

Anzman, Stephanie L., and Leann L. Birch (2009), "Low Inhibitory Control and Restrictive Feeding Practices Predict Weight Outcomes," Journal of Pediatrics, 155 (5), 651-6.

Anzman-Frasca, Stephanie, Cynthia A. Stifter, Ian M. Paul, and Leann L. Birch (2013), "Infant Temperament and Maternal Parenting Self-Efficacy Predict Child Weight Outcomes," Infant Behavior \& Development, 36 (4), 494-7. 
Association for Consumer Research (2016), "Transformative Consumer Research," https://www.acrwebsite.org/web/tcr/transformative-consumer-research.aspx.

Atkin, Charles K. (1978), "Observation of Parent-Child Interaction in Supermarket Decision Making," Journal of Marketing, 42 (4), 41-5.

Aydinoglu, Nilufer Z., and Aradhna Krishna (2011), "Guiltless Gluttony: The Asymmetric Effect of Size Labels on Size Perceptions and Consumption," Journal of Consumer Research, 37 (6), 1095-112.

Badaly, Daryaneh (2013), "Peer Similarity and Influence for Weight-Related Outcomes in Adolescence: A Meta-Analytic Review," Clinical Psychology Review, 33, 1218-36.

Baker, Christina Wood, Todd D. Little and Kelly D. Brownell (2003), "Predicting Adolescent Eating and Activity Behaviors: The Role of Social Norms and Personal Agency," Health Psychology, 22, 189-98.

Barlow, Sarah E. (2007), "Expert Committee Recommendations Regarding the Prevention, Assessment, and Treatment of Child and Adolescent Overweight and Obesity: Summary Report," Pediatrics, 120, S164-92.

Bates, John E., and Gregory S. Petit (2007), "Temperament, Parenting and Socialization," in Handbook of Socialization, ed. Joan E. Grusec and Paul D. Hastings, NY: Guilford, 153-77.

Batsell Jr., W. R., Alan S. Brown, Matthew E. Ansfield, and Gayla Y. Paschall (2002), "You Will Eat All of That! A Retrospective Analysis of Forced Consumption Episodes," Appetite, 38 (3), 211-19.

Baughcum, Amy E., Leigh A. Chamberlin, Cindy M. Deeks, Scott W. Powers, and Robert C. Whitaker (2000), "Maternal Perceptions of Overweight Preschool Children," Pediatrics, 106 (6), 1380-386. 
Baumeister, Roy F. (2002), "Yielding to Temptation: Self-Control Failure, Impulsive

Purchasing, and Consumer Behavior," Journal of Consumer Research, 28 (4), 670-76.

Baumeister, Roy F., and Kathleen D. Vohs (2004), Handbook of Self-regulation: Research,

Theory, and Applications, NY: Guilford.

Baumrind, Diana (1971), "Current Patterns of Parental Authority," Developmental Psychology

Monograph, 4 (1), 1-103.

Beatty, Sharon E., and Salil Talpade (1994), "Adolescent Influence in Family Decision Making:

A Replication with Extension," Journal of Consumer Research, 21 (2), 332-41.

Beck, Paul A., and M. K. Jennings (1991), "Family Traditions, Political Periods, and the

Development of Partisan Orientations," Journal of Politics, 53 (3), 742-63.

Belk, Russell W. (2010), "Sharing," Journal of Consumer Research, 36 (5), 715-34.

Benedikt, Rachel, Eleanor H. Wertheim, and Anthony Love (1998), "Eating Attitudes and

Weight-Loss Attempts in Female Adolescents and Their Mothers," Journal of Youth \& Adolescence, 27 (1), 43-57.

Berge, Jerica M., and Jessie C. Everts (2011), "Family-based Interventions Targeting Childhood Obesity: A Meta-Analysis," Childhood Obesity, 7 (2), 110-21.

Berge, Jerica M., Seth Rowley, Amanda Trofholz, Carrie Hanson, Martha Rueter, Richard F. MacLehose, and Dianne Neumark-Sztainer (2014), "Childhood Obesity and Interpersonal Dynamics During Family Meals," Pediatrics, 134 (5), 923-32.

Bergmeier, Heidi, Helen Skouteris, Sharon Horwood, Merrilyn Hooley, and Ben A. Richardson (2014), "Associations between Child Temperament, Maternal Feeding Practices and Child Body Mass Index during the Preschool Years: A Systematic Review of the Literature," Obesity Reviews, 15 (1), 9-18. 
Beydoun, May A., and Youfa Wang (2009), "Parent-child Dietary Intake Resemblance in the United States: Evidence from a Large Representative Survey," Social Science \& Medicine, 68 (12), 2137-44.

Bickel, Gary, Mark Nord, Cristofer Price, William Hamilton, and John Cook (2000), "Guide to Measuring Household Food Insecurity, Revised 2000," 6, 1-82.

Birch, Leann L. (1998), "Psychological Influences on the Childhood Diet," Journal of Nutrition, 128, 407S-10S.

Birch, Leann L., Jennifer O. Fisher, and Kirsten K. Davison (2003), "Learning to Overeat: Maternal Use of Restrictive Feeding Practices Promotes Girls' Eating in the Absence of Hunger," American Journal of Clinical Nutrition, 78 (2), 215-20.

Birch, Leann L., Diane W. Marlin, and Julie Rotter (1984), "Eating as the 'Means' Activity in a Contingency: Effects on Young Children's Food Preference," Child Development, 55 (2), 431-39.

Birch, Leann L., Jennifer S. Savage, and Jennifer O. Fisher (2015), "Right Sizing Prevention: Food Portion Size Effects on Children's Eating and Weight," Appetite, 88, 11-6.

Blissett, Jackie (2011), "Relationships between Parenting Style, Feeding Style and Feeding Practices and Fruit and Vegetable Consumption in Early Childhood," Appetite, 57 (3), 82631.

Bouchard, Claude (2009), "Childhood Obesity: Are Genetic Differences Involved?" American Journal of Clinical Nutrition, 89 (5), 1494S-501S.

Boutelle, Kerri N., Carol B. Peterson, Ross D. Crosby, Sarah A. Rydell, Nancy Zucker, and Lisa Harnack (2014), "Overeating Phenotypes in Overweight and Obese Children," Appetite, 76, 95-100. 
Braungart-Rieker, Julia M. Jennifer Burke Lefever, Elizabeth M. Planalp and Elizabeth S. Moore (2016) "BMI at Age 3: Cascading Effects of Prenatal Maternal Depression and MotherInfant Dynamics," Journal of Pediatrics, (forthcoming).

Braungart-Rieker, Julia M., Elizabeth S. Moore, Elizabeth M. Planalp, and Jennifer Burke Lefever (2014), "Psychosocial Pathways to Childhood Obesity: A Pilot Study Involving a High Risk Preschool Sample,” Eating Behaviors, 15, 528-31.

Breen, Fiona M., Robert Plomin, and Jane Wardle (2006), "Heritability of Food Preferences in Young Children," Physiology \& Behavior, 88 (4), 443-47.

Brown, Kerry A., Jane Ogden, Claus Vögele, and E. L. Gibson (2008), "The Role of Parental Control Practices in Explaining Children's Diet and BMI," Appetite, 50 (2), 252-59.

Brucks, Merrie (1985), "The Effects of Product Class Knowledge on Information Search Behavior," Journal of Consumer Research, 12 (1), 1-16.

Brucks, Merrie, Gary M. Armstrong, and Marvin E. Goldberg (1988), "Children's Use of Cognitive Defenses against Television Advertising: A Cognitive Response Approach," Journal of Consumer Research, 14 (4), 471-82.

Bruening, Meg, Richard MacLehose, Katie Loth, Mary Story, and Dianne Neumark-Sztainer (2012), "Feeding a Family in a Recession: Food Insecurity among Minnesota Parents," American Journal of Public Health, 102 (3), 520-26.

Burgess-Champoux, Teri, Nicole Larson, Dianne Neumark-Sztainer, Peter J. Hannan, and Mary Story (2009), "Are Family Meal Patterns Associated with Overall Diet Quality During the Transition from Early to Middle Adolescence?" Journal of Nutrition Education \& Behavior, $41(2), 79-86$. 
Bzostek, Sharon H., and Audrey N. Beck (2011), "Familial Instability and Young Children’s Physical Health," Social Science \& Medicine, 73 (2), 282-92.

Campbell, Karen J., Gavin Abbott, Alison C. Spence, David A. Crawford, Sarah A.

McNaughton, and Kylie Ball (2013), "Home Food Availability Mediates Associations between Mothers' Nutrition Knowledge and Child Diet," Appetite, 71(December), 1-6.

Campbell, Karen, Nick Andrianopoulos, Kylie Hesketh, Kylie Ball, David Crawford, Leah Brennan, Nadia Corsini, and Anna Timperio (2010), "Parental Use of Restrictive Feeding Practices and Child BMI Z-Score. A 3-year Prospective Cohort Study," Appetite, 55 (1), 848.

Campbell, Margaret C., and Gina S. Mohr (2011), "Seeing is Eating: How and When Activation of a Negative Stereotype Increases Stereotype-Conductive Behavior," Journal of Consumer Research, 38 (3), 431-44.

Cardel, Michelle, Amanda L. Willig, Akilah Dulin-Keita, Krista Casazza, T.Mark Beasley, and José R. Fernández (2012), "Parental Feeding Practices and Socioeconomic Status Are Associated with Child Adiposity in a Multi-Ethnic Sample of Children," Appetite, 58 (1), 347-53.

Carey, William B., Robin L. Hegvik, and Sean C. McDevitt (1988), "Temperamental Factors Associated with Rapid Weight Gain and Obesity in Middle Childhood," Journal of Developmental and Behavioral Pediatrics, 9 (4), 194-98.

Carlson, Jay P., Leslie H. Vincent, David M. Hardesty, and William O. Bearden (2009), "Objective and Subjective Knowledge Relationships: A Quantitative Analysis of Consumer Research Findings," Journal of Consumer Research, 35 (5), 864-76. 
Carlson, Les, and Sanford Grossbart (1988), "Parental Style and Consumer Socialization of Children," Journal of Consumer Research, 15 (1), 77-94.

Carnell, Susan, Claire M.A. Haworth, Robert Plomin, and Jane Wardle (2008), "Genetic Influence on Appetite in Children," International Journal of Obesity, 32 (10), 1468-73.

Carnell, Susan, Yale Kim, and Katherine Pryor (2012), "Fat Brains, Greedy Genes, and Parent Power: A Biobehavioural Risk Model of Child and Adult Obesity," International Review of Psychiatry, 24 (3), 189-99.

Carnell, Susan, and Jane Wardle (2007), "Associations between Multiple Measures of Parental Feeding and Children's Adiposity in United Kingdom Preschoolers," Obesity, 15 (1), 13744.

Chandon, Pierre, and Brian Wansink (2007), "The Biasing Health Halos of Fast-Food Restaurant Health Claims: Lower Calorie Estimates and Higher Side-Dish Consumption Intentions," Journal of Consumer Research, 34 (3), 301-14.

Chaplin, Lan Nguyen and Deborah Roedder John (2005), "The Development of Self-Brand Connections in Children and Adolescents," Journal of Consumer Research, 32 (1), 119-29. Childers, Terry L., and Akshay R. Rao (1992), "The Influence of Familial and Peer-Based Reference Groups on Consumer Decisions," Journal of Consumer Research, 19 (2), 198211.

Connell, Paul M., Merrie Brucks, and Jesper H. Nielsen (2014), "How Childhood Advertising Exposure Can Create Biased Product Evaluations That Persist Into Adulthood," Journal of Consumer Research, 41 (1), 119-34. 
Contento, Isobel R., Charles Basch, Steven Shea, Bernard Gutin, Patricia Zybert, John L. Michela, and Jill Rips (1993), "Relationship of Mothers' Food Choice Criteria to Food Intake of Preschool Children: Identification of Family Subgroups," Health Education Quarterly, 20 (2), 243-59.

Corder, Kirsten, Esther M. F. van Sluijs, Alison M. McMinn, Ulf Ekelund, Aedin Cassidy, and Simon J. Griffin (2010), "Perception Versus Reality: Awareness of Physical Activity Levels of British Children," American Journal of Preventive Medicine, 38 (1), 1-8.

Cotte, June, and Stacy L. Wood (2004), "Families and Innovative Consumer Behavior: A Triadic Analysis of Sibling and Parental Influence," Journal of Consumer Research, 31 (1), 78-86.

Craggs, Christopher, Kirsten Corder, Esther M. F. van Sluijs, and Simon J. Griffin (2011), "Determinants of Change in Physical Activity in Children and Adolescents: A Systematic Review," American Journal of Preventive Medicine, 40 (6), 645-58.

Cross, Matthew B., Allen M. Hallett, Tracey A. Ledoux, Daniel P. O'Connor, and Sheryl O. Hughes (2014), "Effects of Children's Self-Regulation of Eating on Parental Feeding Practices and Child Weight," Appetite, 81, 76-83.

Daly, Kerry J. (1996), Families \& Time: Keeping Pace in a Harried Culture, Thousand Oaks, CA: Sage. (2001), "Deconstructing Family Time: From Ideology to Lived Experience," Journal of Marriage \& Family, 63 (2), 283-94.

----------- (2003), "Family Theory Versus the Theories Families Live By," Journal of Marriage \& Family, 65 (4), 771-84. 
Dammann, Kristen W., Chery Smith, and Rickelle Richards (2011), "Low-Income Minority and Homeless Mothers' Perceptions of Their 9-13 Year-Old Children's Weight Status, Diet, and Health." Maternal \& Child Health Journal, 15 (1), 106-14.

Darling, Nancy, and Laurence Steinberg (1993), "Parenting Style as Context: An Integrative Model," Psychological Bulletin, 113 (3), 487-96.

Davison, Kirsten K., and Catherine T. Lawson (2006), "Do Attributes in the Physical Environment Influence Children's Physical Activity? A Review of the Literature," The International Journal of Behavioral Nutrition and Physical Activity, 3 (19), 1-17.

De Bourdeaudhuij, Ilse, Saskia J. Te Velde, Lea Maes, Carmen Pérez-Rodrigo, Maria D. V. de Almeida, and Johannes Brug (2009), "General Parenting Styles Are Not Strongly Associated with Fruit and Vegetable Intake and Social-Environmental Correlates among 11 Year-old Children in Four Countries in Europe," Public Health Nutrition, 12 (2), 259-66.

Dewitte, Siegfried, Sabrina Bruyneel, and Kelly Geyskens (2009), "Self-Regulating Enhances Self-Regulation in Subsequent Consumer Decisions Involving Similar Response Conflicts," Journal of Consumer Research, 36 (3), 394-405.

Dietz, William H. (1994), "Critical Periods in Childhood for the Development of Obesity," American Journal of Clinical Nutrition, 59 (5), 955-59.

Dishman, Rod K., Ruth P. Saunders, Robert W. Motl, Marsha Dowda, and Russell R. Pate (2009), "Self-Efficacy Moderates the Relation between Declines in Physical Activity and Perceived Social Support in High School Girls," Journal of Pediatric Psychology, 34 (4), 441-51. 
Doolen, Jessica, Patricia T. Alpert, and Sally K. Miller (2009), "Parental Disconnect between Perceived and Actual Weight Status of Children: A Metasynthesis of the Current Research," Journal of the American Academy of Nurse Practitioners, 21 (3), 160-66.

Dowda, Marsha, Rod K. Dishman, Karin A. Pfeiffer, and Russell R. Pate (2007), "Family Support for Physical Activity in Girls from 8th to 12th Grade in South Carolina," Preventive Medicine, 44 (2), 153-59.

Drake, Keith M., Michael L. Beach, Meghan R. Longacre, Todd Mackenzie, Linda J. Titus, Andrew G. Rundle, and Madeline A. Dalton (2012), "Influence of Sports, Physical Education, and Active Commuting to School on Adolescent Weight Status," Pediatrics, 130 (2), e296-e304.

Dubois, Lise, Kirsten O. Kyvik, Manon Girard, Fabiola Tatone-Tokuda, Daniel Pérusse, Jacob Hjelmborg, Axel Skytthe, Finn Rasmussen, Margaret J. Wright, Paul Lichtenstein, and Nicholas G. Martin (2012), "Genetic and Environmental Contributions to Weight, Height, and BMI From Birth to 19 Years of Age: An International Study of Over 12,000 Twin Pairs," Plos One, 7 (2), 1-12.

Eaton, Danice K., Laura Kann, Steve Kinchen, Shari Shanklim, James Ross, Joseph Hawkins, William A. Harris, Richard Lowry, Tim McManus, David Chyen, Connie Lim, Lisa Whittle, Nancy D. Brener, and Howell Wechsler (2010), "Youth Risk Behavior Surveillance - United States, 2009," Morbidity and Mortality Weekly Report, 59 (SS-5), 1-30.

Eckstein, Kathryn C., Laura M. Mikhail, Adolfo J. Ariza, J. S. Thomson, Scott C. Millard, and Helen J. Binns (2006), "Parents' Perceptions of Their Child's Weight and Health," Pediatrics, 117 (3), 681-90. 
Eisenberg, Marla E., Rachel E. Olson, Dianne Neumark-Sztainer, Mary Story, and Linda H.

Bearinger (2004), "Correlations between Family Meals and Psychosocial Well-Being among Adolescents," Archives of Pediatrics \& Adolescent Medicine, 158 (8), 792-96.

Eisenberg, Nancy, Cynthia L. Smith, Adrienne Sadovsky, and Tracy L. Spinrad (2004), "Effortful Control - Relations with Emotion Regulation, Adjustment and Socialization in Childhood," in Handbook of Self-regulation: Research, Theory and Applications, ed., Roy F. Baumeister and Kathleen D. Vohs, New York, NY: Guilford Press, 259-82.

Eisenmann, Joey C., Craig Gundersen, Brenda J. Lohman, Steven Garasky, and Susan D.

Stewart (2011), "Is Food Insecurity Related to Overweight and Obesity in Children and Adolescents? A Summary of Studies, 1995-2009," Obesity Reviews, 12, e73-e83.

Ekstrom, Karin M. (2006), "Consumer Socialization Revisited," Research in Consumer Behavior, 10, 71-98.

Ellis, Renee R. and Tavia Simmons (2014), “Coresident Grandparents and Their Grandchildren: 2012,” Current Population Reports, P20-576, U.S. Census Bureau, Washington, DC.

Epp, Amber M., and Linda L. Price (2008), "Family Identity: A Framework of Identity Interplay in Consumption Practices," Journal of Consumer Research, 35 (1), 50-70. (2011), "Designing Solutions Around Customer Network Identity Goals," Journal of Marketing, 75 (2), 36-54.

---------------- (2012), "Family Time in Consumer Culture - Implications for Transformative Consumer Research," in Transformative Consumer Research for Personal and Collective Well-being, ed. David Glen Mick, Simone Pettigrew, Cornelia Pechmann and Julie L. Ozanne, NY: Routledge, 599-622. 
Epp, Amber M., Hope Jensen Schau, and Linda L. Price (2014), "The Role of Brands and Mediating Technologies in Assembling Long-Distance Family Practices," Journal of Marketing, 78 (3), 81-101.

Epstein, Leonard H., Kelly K. Dearing, and Richard W. Erbe (2010), "Parent-Child Concordance of Taq1 A1 Allele Predicts Similarity of Parent-Child Weight Loss in Behavioral Family-Based Treatment Programs," Appetite, 55 (2), 363-66.

Esposito, Layla, Jennifer O. Fisher, Julie A. Mennella, Deanna M. Hoelscher, and Terry T. Huang (2009), "Developmental Perspectives on Nutrition and Obesity from Gestation to Adolescence," Preventing Chronic Disease, 6 (3), 1-11.

Evans, Gary W., McKenzie Jones-Rounds, Goran Belojevic, and Francoise Vermeylen (2012), "Family Income and Childhood Obesity in Eight European Cities: The Mediating Roles of Neighborhood Characteristics and Physical Activity," Social Science \& Medicine, 75 (3), $477-81$.

Faber, Ronald J., Gary A. Christenson, Martina De Zwaan, and James Mitchell (1995), "Two Forms of Compulsive Consumption: Comorbidity of Compulsive Buying and Binge Eating." Journal of Consumer Research, 22 (3), 296-304.

Faith, Myles S., Robert I. Berkowitz, Virginia A. Stallings, Julia Kerns, Megan Storey, and Albert J. Stunkard (2004), "Parental Feeding Attitudes and Styles and Child Body Mass Index: Prospective Analysis of a Gene-Environment Interaction," Pediatrics, 114 (4), e42936.

Faith, Myles S., Susan Carnell, and Tanja V. E. Kral (2013), "Genetics of Food Intake SelfRegulation in Childhood: Literature Review and Research Opportunities," Human Heredity, $75(2-4), 80-9$. 
Faith, Myles S., Kelley S. Scanlon, Leann L. Birch, Lori A. Francis, and Bettylou Sherry (2004), "Parent-Child Feeding Strategies and Their Relationships to Child Eating and Weight Status," Obesity Research, 12 (11), 1711-722.

Faith, Myles S., Linda Van Horn, Lawrence J. Appel, Lora E. Burke, Jo A. S. Carson, Harold A. Franch, John M. Jakicic, Tanja V. E. Kral, Angela Odoms-Young, Brian Wansink, and Judith Wylie-Rosett (2012), "Evaluating Parents and Adult Caregivers as "Agents of Change" for Treating Obese Children: Evidence for Parent Behavior Change Strategies and Research Gaps: A Scientific Statement from the American Heart Association," Circulation, 125 (9), 1186-1207.

Falciglia, Grace A., Stephanie Pabst, Sarah C. Couch, and Cynthia Goody (2004), "Impact of Parental Food Choices on Child Food Neophobia," Children's Health Care, 33 (3), 217-25. Farrow, Claire V. (2012), "Do Parental Feeding Practices Moderate the Relationships between Impulsivity and Eating in Children?" Eating Behaviors, 13 (2), 150-53.

Federal Trade Commission (2012), A Review of Food Marketing to Children and Adolescents: Follow-up Report, Washington, DC.

Fiese, Barbara H., Amber Hammons, and Diana Grigsby-Toussaint (2012), "Family Mealtimes: A Contextual Approach to Understanding Childhood Obesity," Economics and Human Biology, 10 (4), 365-74.

Fiese, Barbara H., Thomas J. Tomcho, Michael Douglas, Kimberly Josephs, Scott Poltrock, and Tim Baker (2002), "A Review of 50 Years of Research on Naturally Occurring Family Routines and Rituals: Cause for Celebration?" Journal of Family Psychology, 16 (4), 38190. 
Finkelstein, Stacey R., and Ayelet Fishbach (2010), "When Healthy Food Makes You Hungry," Journal of Consumer Research, 37 (3), 357-67.

Fisher, Jennifer O. and Tanja V.E. Kral (2008), “Super-size Me: Portion Size Effects on Young Children's Eating," Physiology \& Behavior, 94 (1), 39-47.

Fisher, Jennifer O., and Leann L. Birch (1999), "Restricting Access to Palatable Foods Affects Children's Behavioral Response, Food Selection, and Intake," American Journal of Clinical Nutrition, 69 (6), 1264-272.

Fisher, Jennifer O., Diane C. Mitchell, Helen Smiciklas-Wright, Michelle L. Mannino, and Leann L. Birch (2004), "Meeting Calcium Recommendations During Middle Childhood Reflects Mother-Daughter Beverage Choices and Predicts Bone Mineral Status," American Journal of Clinical Nutrition, 79 (4), 698-706.

Fogelholm, Mikael, Outi Nuutinen, Matti Pasanen, E. Myöhänen, and T. Säätelä (1999), "Parent-Child Relationship of Physical Activity Patterns and Obesity," International Journal of Obesity \& Related Metabolic Disorders, 23 (12), 1262-268.

Fox, Mary K., Barbara Devaney, Kathleen Reidy, Carol Razafindrakoto, and Paula Ziegler (2006), "Relationship between Portion Size and Energy Intake among Infants and Toddlers: Evidence of Self-regulation," Journal of the American Dietetic Association, 106, s77-83.

Francis, Lori A., and Leann L. Birch (2005), "Maternal Influences on Daughters' Restrained Eating Behavior," Health Psychology, 24 (6), 548-54.

Francis, Lori A., and Elizabeth J. Susman (2009), "Self-Regulation and Rapid Weight Gain in Children from Age 3 to 12 Years," Archives of Pediatrics \& Adolescent Medicine, 163 (4), 297-302. 
Francis, Lori A., Alison K. Ventura, Michele Marini, and Leann L. Birch (2007), "Parent Overweight Predicts Daughters' Increase in BMI and Disinhibited Overeating from 5 to 13 Years," Obesity, 15 (6), 1544-553.

Frankel, Leslie A., Sheryl O. Hughes, Teresia M. O'Connor, Thomas G. Power, Jennifer O. Fisher, and Nancy L. Hazen (2012), "Parental Influences on Children's Self-Regulation of Energy Intake: Insights from Developmental Literature on Emotion Regulation," Journal of Obesity, 1-12.

Frankel, Leslie A., Teresia M. O’Connor, Tzu-An Chen, Theresa Nicklas, Thomas G. Power, and Sheryl O. Hughes (2014), "Parents' Perceptions of Preschool Children's Ability To Regulate Eating. Feeding Style Differences," Appetite, 76, 166-74.

Fraser, Josephine, Helen Skouteris, Marita Mccabe, Lina A. Ricciardelli, Jeannette Milgrom, and Louise A. Baur (2011), "Paternal Influences on Children's Weight Gain: A Systematic Review," Fathering, 9 (3), 252-67.

Freedman, David S., Laura K. Khan, Mary K. Serdula, William H. Dietz, Sathanur R. Srinivasan, and Gerald S. Berenson (2005a), "Racial Differences in the Tracking of Childhood BMI to Adulthood," Obesity Research, 13 (5), 928-35. (2005b), "The Relation of Childhood BMI to Adult Adiposity: The Bogalusa

Heart Study," Pediatrics, 115 (1), 22-7.

Freedman, David S., Zuguo Mei, Sathanur R. Srinivasan, Gerald S. Berenson, and William H. Dietz (2007), "Cardiovascular Risk Factors and Excess Adiposity among Overweight Children and Adolescents: The Bogalusa Heart Study," Journal of Pediatrics, 150 (1), 12-7. 
Friedman, Margaret L., and Gilbert A. Churchill Jr. (1987), "Using Consumer Perceptions and a Contingency Approach to Improve Health Care Delivery," Journal of Consumer Research, $13(4), 492-510$.

Fulkerson, Jayne A., Maureen T. McGuire, Dianne Neumark-Sztainer, Mary Story, Simone A. French, and Cheryl L. Perry (2002), "Weight-Related Attitudes and Behaviors of Adolescent Boys and Girls Who Are Encouraged to Diet by Their Mothers," International Journal of Obesity \& Related Metabolic Disorders, 26 (12), 1579-587.

Gal, David, and Wendy Liu (2011), "Grapes of Wrath: The Angry Effects of Self-Control," Journal of Consumer Research, 38 (3), 445-58.

Galloway, Amy T., Laura M. Fiorito, Lori A. Francis, and Leann L. Birch (2006), "'Finish Your Soup': Counterproductive Effects of Pressuring Children to Eat on Intake and Affect," Appetite, 46 (3), 318-23.

Galst, Joann P., and Mary A. White (1976), "The Unhealthy Persuaders: The Reinforcing Value of Television and Children's Purchase-Influencing Attempts at the Supermarket," Child Development, 47 (4), 1089-096.

Galvin, Kathleen M., Dawn O. Braithwaite, and Carma L. Bylund (2015), Family Communication: Cohesion and Change, 9th ed. Boston, MA: Pearson.

Galvin, Kathleen M., Fran C. Dickson, and Sherilyn R. Marrow (2006), "Systems Theory: Patterns and (W)holes in Family Communication," in Engaging Theories in Family Communications, ed. Dawn O. Braithwaite, and Leslie A. Baxter. Thousand Oaks, CA: Sage, 309-23. 
Garcia-Bailo, Bibiana, Clare Toguri, Karen M. Eny, and Ahmed El-Sohemy (2009), "Genetic Variation in Taste and Its Influence on Food Selection," Omics: A Journal of Integrative Biology, 13 (1), 69-80.

Garg, Nitika, Brian Wansink, and J. Jeffrey Inman (2007), "The Influence of Incidental Affect on Consumers' Food Intake," Journal of Marketing, 71 (1), 194-206.

Gaumer, Carol J., and Carol Arnone (2010), "Grocery Store Observation: Parent-Child Interaction in Family Purchases," Journal of Food Products Marketing, 16 (1), 1-18.

Geller, Josie, Suja Srikameswaran, Shannon L. Zaitsoff, Sarah J. Cockell, and Gary D. Poole (2003), "Mothers' and Fathers' Perceptions of Their Adolescent Daughters' Shape, Weight, and Body Esteem: Are They Accurate?" Journal of Youth \& Adolescence, 32 (2), 81-87.

Gholami, Maryam, Amelie Wiedemann, Nina Knoll, and Ralf Schwarzer (2015), "Mothers Improve Their Daughters' Vegetable Intake: A Randomized Controlled Trial," Psychology, Health \& Medicine, 20 (1), 1-7.

Graziano, Paulo A., Rachael Kelleher, Susan D. Calkins, Susan P. Keane, and Marion O. Brien (2013), "Predicting Weight Outcomes in Preadolescence: The Role of Toddlers' SelfRegulation Skills and the Temperament Dimension of Pleasure," International Journal of Obesity, 37 (7), 937-42.

Gregan-Paxton, Jennifer, and Deborah R. John (1997), "The Emergence of Adaptive Decision Making in Children," Journal of Consumer Research, 24 (1), 43-56.

Grier, Sonya A., Janell Mensinger, Shirley H. Huang, Shiriki K. Kumanyika, and Nicolas Stettler (2007), "Fast-Food Marketing and Children's Fast-Food Consumption: Exploring Parents' Influences in an Ethnically Diverse Sample," Journal of Public Policy \& Marketing, 26 (2), 221-35. 
Grier, Sonya A., and Elizabeth S. Moore (2012), "Tackling the Childhood Obesity Epidemic An Opportunity for Transformative Consumer Research," in Transformative Consumer Research for Personal and Collective Well-being, ed. David Glen Mick, Simone Pettigrew, Cornelia Pechmann and Julie L. Ozanne, NY: Routledge, 303-32.

Grolnick, Wendy S., Edward L. Deci, and Richard M. Ryan (1997), "Internalization within the Family: The Self-Determination Theory Perspective," in Parenting and Children's Internalization of Values - A Handbook of Contemporary Theory, ed. Joan E. Grusec, and Leon Kuczynski, NY: John Wiley \& Sons, 135-61.

Grusec, Joan E., and Maayan Davidov (2007), "Socialization in the Family- The Roles of Parents," in Handbook of Socialization Theory and Research, ed. Joan E. Grusec, and Paul D. Hastings, NY: Guilford, 284-308.

Gubbels, Jessica S., Stef P.J. Kremers, Annette Stafleu, Pieter C. Dagnelie, R. Alexandra Goldbohm, Nanne K. de Vries, and Carel Thijs (2009), "Diet-related Restrictive Parenting Practices: Impact on Dietary Intake of 2 Year-old Children and Interactions with Child Characteristics," Appetite, 52 (2), 423-29.

Haines, Jess, Julia McDonald, Ashley O'Brien, Bettylou Sherry, Clement J. Bottino, Marie E. Schmidt, and Elsie M. Taveras (2013), "Healthy Habits, Happy Homes: Randomized Trial to Improve Household Routines for Obesity Prevention among Preschool-Aged Children," JAMA Pediatrics, 167 (11), 1072-079.

Hall, Laura, Clare E. Collins, Philip J. Morgan, Tracy L. Burrows, David R. Lubans, and Robin Callister (2011), "Children's Intake of Fruit and Selected Energy-Dense Nutrient-Poor Foods is Associated with Fathers' Intake," Journal of the American Dietetic Association, 111 (7), $1039-44$. 
Hammons, Amber J., and Barbara H. Fiese (2011), "Is Frequency of Shared Family Meals Related to the Nutritional Health of Children and Adolescents?" Pediatrics, 127 (6), e1565574.

Han, Joan C., Debbie A. Lawlor, and Sue S. Kimm (2010), "Childhood Obesity." The Lancet, 375 (9727), 1737-748.

Hansen, Andrew R., Dustin T. Duncan, Yelena N. Tarasenko, Fei Yan, and Jian Zhang (2014), "Generational Shift in Parental Perceptions of Overweight among School-Aged Children," Pediatrics, 134 (3), 481-88.

Hanson, Nicole I., Dianne Neumark-Sztainer, Marla E. Eisenberg, Mary Story, and Melanie Wall (2005), "Associations between Parental Report of the Home Food Environment and Adolescent Intakes of Fruits, Vegetables and Dairy Foods," Public Health Nutrition, 8 (1), 77-85.

Harrist, Amanda W., Glade L. Topham, Laura Hubbs-Tait, Melanie C. Page, Tay S. Kennedy, and Lenka H. Shriver (2012), "What Developmental Science Can Contribute to a Transdisciplinary Understanding of Childhood Obesity: An Interpersonal and Intrapersonal Risk Model," Child Development Perspectives, 6 (4), 445-55.

Harvard School of Public Health (2013), A Poll about Children and Weight: Crunch Time During the American Work and School Week - 3PM to Bed, unpublished paper, Harvard School of Public Health, NPR, Robert Wood Johnson Foundation.

Hennessy, Erin, Sheryl O. Hughes, Jeanne P. Goldberg, Raymond R. Hyatt, and Christina D. Economos (2010), "Parent-Child Interactions and Objectively Measured Child Physical Activity: A Cross-Sectional Study," International Journal of Behavioral Nutrition \& Physical Activity, 7, 71-84. 
Hernandez, Daphne C., and Emily Pressler (2014), "Accumulation of Childhood Poverty on Young Adult Overweight or Obese Status: Race/Ethnicity and Gender Disparities," Journal of Epidemiology and Community Health, 68 (5), 478-84.

Hernandez, Daphne C., Emily Pressler, Cassandra Dorius, and Katherine S. Mitchell (2014), "Does Family Instability Make Girls Fat? Gender Differences between Instability and Weight," Journal of Marriage \& Family, 76 (1), 175-90.

Hernandez, Raquel G., Darcy A. Thompson, Tina L. Cheng, and Janet R. Serwint (2012), "EarlyChildhood Obesity: How Do Low-Income Parents of Preschoolers Rank Known Risk Factors?" Clinical Pediatrics, 51 (7), 663-70.

Hill, Claire, Clare H. Llewellyn, J. Saxton, Laura Webber, C. Semmler, Susan Carnell, C. H. M. van Jaarsveld, D. Boniface, and J. Wardle (2008), "Adiposity and 'Eating in the Absence of Hunger' in Children," International Journal of Obesity, 32 (10), 1499-505.

Hoch, Stephen J., and George F. Loewenstein (1991), "Time-Inconsistent Preferences and Consumer Self-Control," Journal of Consumer Research, 17 (4), 492-507.

Holden, George W., and Pamela C. Miller (1999), "Enduring and Different: A Meta-Analysis of the Similarity in Parents' Child Rearing," Psychological Bulletin, 125 (2), 223-54.

Hood, Maggie Y., Lynn L. Moore, Anuradha Sundarajan-Ramamurti, Martha L. Singer, L. Adrienne Cupples, and Robert C. Ellison (2000), "Parental Eating Attitudes and the Development of Obesity in Children: The Framingham Children's Study," International Journal of Obesity \& Related Metabolic Disorders, 24 (10), 1319-25.

Hughes, Sheryl O., Thomas G. Power, Jennifer O. Fisher, Stephen Mueller, and Theresa A. Nicklas (2005), "Revisiting a Neglected Construct: Parenting Styles in a Child-Feeding Context," Appetite, 44 (1), 83-92. 
Hung, Iris W., and Aparna A. Labroo (2011), "From Firm Muscles to Firm Willpower: Understanding the Role of Embodied Cognition in Self-Regulation," Journal of Consumer Research, 37 (6), 1046-64.

Irmack, Caglar, Beth Vallen, and Stefanie R. Robinson (2011), "The Impact of Product Name on Dieters' and Nondieters' Food Evaluations and Consumption," Journal of Consumer Research, 38 (2), 390-405.

Isler, Leslie, Edward T. Popper, and Scott Ward (1987), "Children's Purchase Requests and Parental Responses: Results From a Diary Study," Journal of Advertising Research, 27 (5), 28-39.

Jago, Russell, Kirsten K. Davison, Rowan Brockman, Angie S. Page, Janice L. Thompson, and Kenneth R. Fox (2011), "Parenting Styles, Parenting Practices, and Physical Activity in 10to 11-Year Olds," Preventive Medicine, 52 (1), 44-7.

Jain, Anjali, Leigh A. Chamberlin, Yvette Carter, Scott W. Powers, and Robert C. Whitaker (2001), "Why Don't Low-Income Mothers Worry About Their Preschoolers Being Overweight?" Pediatrics, 107 (5), 1138-146.

John, Deborah R. (1999), "Consumer Socialization of Children: A Retrospective Look at Twenty-Five Years of Research," Journal of Consumer Research, 26 (3), 183-213. Johnson, Susan L., Sheryl O. Hughes, Xiangqin Cui, Xuelin Li, David B. Allison, Yan Liu, L. S. Goodell, Theresa Nicklas, Thomas G. Power, and Kirstin Vollrath (2014), "Portion Sizes for Children are Predicted by Parental Characteristics and the Amounts Parents Serve Themselves," American Journal of Clinical Nutrition, 99 (4), 763-70. 
Johnston, Lloyd D., Jorge Delva, and Patrick M. O’Malley (2007), "Sports Participation and Physical Education in American Secondary Schools: Current Levels and Racial/Ethnic and Socioeconomic Disparities," American Journal of Preventive Medicine, 33 (4), S195-208.

Jones, Tracy L., and Ronald J. Prinz (2005), "Potential Roles of Parental Self-efficacy in Parent and Child Adjustment: A Review," Clinical Psychology Review, 25 (3), 341-63.

Kahn, Barbara E., and Brian Wansink (2004), "The Influence of Assortment Structure on Perceived Variety and Consumption Quantities," Journal of Consumer Research, 30 (4), 519-33.

Koplan, Jeffrey P., and William H. Dietz (1999), "Caloric Imbalance and Public Health Policy," Journal of the American Medical Association, 282 (16), 1579-581.

Kral, Tanja V. E., David B. Allison, Leann L. Birch, Virginia A. Stallings, Reneé H. Moore, and Myles S. Faith (2012), "Caloric Compensation and Eating in the Absence of Hunger in 5- to 12-year-old Weight-Discordant Siblings," American Journal of Clinical Nutrition, 96 (3), 574-83.

Kral, Tanja V. E., April C. Kabay, Liane S. Roe, and Barbara J. Rolls (2010), "Effects of Doubling the Portion Size of Fruit and Vegetable Side Dishes on Children's Intake at a Meal," Obesity, 18 (3), 521-27.

Kreider, Rose M., and Renee Ellis (2011), "Living Arrangements of Children: 2009," Current Population Reports, P70-126, U. S. Census Bureau, Washington, DC.

Krishnamurthy, Parthasarathy, and Sonja Prokopec (2010), "Resisting that Triple-Chocolate Cake: Mental Budgets and Self-Control," Journal of Consumer Research, 37 (1), 68-79. Kumanyika, Shiriki K. (2008), "Environmental Influences on Childhood Obesity: Ethnic and Cultural Influences in Context," Physiology \& Behavior, 94 (1), 61-70. 
Labroo, Aparna A., and Anirban Mukhopadhyay (2009), "Lay Theories of Emotion Transience and the Search for Happiness: A Fresh Perspective on Affect Regulation," Journal of Consumer Research, 36 (2), 242-54.

Larson, Nicole I., Dianne Neumark-Sztainer, Peter J. Hannan, and Mary Story (2007), "Family Meals During Adolescence Are Associated with Higher Diet Quality and Healthful Meal Patterns During Young Adulthood," Journal of the American Dietetic Association, 107 (9), $1502-10$.

Larson, Nicole I., Mary Story, Marla E. Eisenberg, and Dianne Neumark-Sztainer (2006), "Food Preparation and Purchasing Roles among Adolescents: Associations with Sociodemographic Characteristics and Diet Quality," Journal of the American Dietetic Association, 106 (2), 211-18.

Lau, Richard R., Marilyn Jacobs Quadrel and Karen A. Hartman (1990), "Development and Change of Young Adults' Preventive Health Beliefs and Behavior: Influence from Parents and Peers," Journal of Health and Social Behavior, 31 (September), 240-59.

Leahy, Kathleen E., Leann L. Birch, Jennifer O. Fisher, and Barbara J. Rolls (2008), "Reductions in Entrée Energy Density Increase Children's Vegetable Intake and Reduce Energy Intake," Obesity, 16 (7), 1559-565.

Lee, SoJung, and Silva A. Arslanian (2008), "Fat Oxidation in Black and White Youth: A Metabolic Phenotype Potentially Predisposing Black Girls to Obesity." Journal of Clinical Endocrinology and Metabolism, 93 (11), 4547-551.

Lightfoot, J. T. (2011), "Current Understanding of the Genetic Basis for Physical Activity," Journal of Nutrition, 141 (3), 526-30. 
Lissau, Inge, Leif Breum, and Thorkild I. A. Sørensen (1993), "Maternal Attitude to Sweet Eating Habits and Risk of Overweight in Offspring: A Ten-Year Prospective Population Study," International Journal of Obesity \& Related Metabolic Disorders, 17 (3), 125-29. Llewellyn, Clare H., Cornelia van Jaarsveld H.M., David Boniface, Susan Carnell, and Jane Wardle (2008), "Eating Rate is a Heritable Phenotype Related to Weight in Children," American Journal of Clinical Nutrition, 88 (6), 1560-566.

Lopez-Dicastillo, Olga, Gunn Grande, and Peter Callery (2010), "Parents' Contrasting Views on Diet versus Activity of Children: Implications for Health Promotion and Obesity Prevention." Patient Education and Counseling, 78 (1), 117-23.

Luttikhuis, H.G.M. Oude, Ronald P. Stolk, and Pieter J. J. Sauer (2010), "How Do Parents of 4 to 5 Year-Old Children Perceive the Weight of their Children?" Acta Paediatrica, 99 (2), 263-67.

Lytle, Leslie A., Mary O. Hearst, Jayne Fulkerson, David M. Murray, Brian Martinson, Elizabeth Klein, Keryn Pasch, and Anne Samuelson (2011), "Examining the Relationships between Family Meal Practices, Family Stressors, and the Weight of Youth in the Family," Annals of Behavioral Medicine, 41 (3), 353-62.

Maccoby, Eleanor E. (2007), "Historical Overview of Socialization Research and Theory," in Handbook of Socialization: Theory and Research, ed. Joan E. Grusec, and Paul D. Hastings, NY: Guilford, 13-41.

Mackey, Eleanor R., and Annette La Greca M. (2007), "Adolescents' Eating, Exercise, and Weight Control Behaviors: Does Peer Crowd Affiliation Play a Role?" Journal of Pediatric Psychology, 32 (1), 13-23. 
Mallan, Kimberley M., Lynne A. Daniels, Michaela Nothard, Jan M. Nicholson, Andrew Wilson, Cate M. Cameron, Paul A. Scuffham and Karen Thorpe (2014), "Dads at the Dinner Table: A Cross-sectional Study of Australian Fathers' Child Feeding Perceptions and Practices," Appetite, 73 (1), 40-4.

Manco, Melania, and Bruno Dallapiccola (2012), "Genetics of Pediatric Obesity," Pediatrics, $130(1), 123-33$.

Mathias, Kevin C., Barbara J. Rolls, Leann L. Birch, Tanja V. E. Kral, Elizabeth L. Hanna, Adam Davey, and Jennifer O. Fisher (2012), "Serving Larger Portions of Fruits and Vegetables Together at Dinner Promotes Intake of Both Foods among Young Children," Journal of the Academy of Nutrition \& Dietetics, 112 (2), 266-70.

Maubach, Ninya, Janet Hoek, and Tim McCreanor (2009), "An Exploration of Parents' Food Purchasing Behaviours," Appetite, 53 (3), 297-302.

May, Ashleigh L., Ji-Yeon Kim, Susan M. McHale, and Ann C. Crouter (2006), "ParentAdolescent Relationships and the Development of Weight Concerns From Early To Late Adolescence," International Journal of Eating Disorders, 39 (8), 729-40.

Maynard, L. M., Deborah A. Galuska, Heidi M. Blanck, and Mary K. Serdula (2003), "Maternal Perceptions of Weight Status of Children," Pediatrics, 111 (5), 1226.

McCabe, Lisa A., Marisol Cunningham, and Jeanne Brooks-Gunn (2004), "The Development of Self-Regulation in Children," in Handbook of Self-Regulation, ed. Roy F. Baumeister and Kathleen D. Vohs, NY: Guilford, 340-56.

McFerran, Brent, Darren W. Dahl, Gavan J. Fitzsimons, and Andrea C. Morales (2010), "I'll Have What She's Having: Effects of Social Influence and Body Type on the Food Choices of Others," Journal of Consumer Research, 36 (6), 915-29. 
McGinnis, J. M., Jennifer A. Gootman, and Vivica I. Kraak (2006), Food Marketing to Children and Youth: Threat or Opportunity? Washington, DC: Institute of Medicine, National Academies Press.

Mellin, Alison E., Dianne Neumark-Sztainer, Mary Story, Marjorie Ireland, and Michael D. Resnick (2002), "Unhealthy Behaviors and Psychosocial Difficulties among Overweight Adolescents: The Potential Impact of Familial Factors," Journal of Adolescent Health, 31 (2), 145-53.

Menning, Chadwick L., and Susan D. Stewart (2008), "Nonresident Father Involvement, Social Class, and Adolescent Weight," Journal of Family Issues, 29 (12), 1673-700.

Metallinos-Katsaras, Elizabeth, Aviva Must, and Kathleen Gorman (2012), "A Longitudinal Study of Food Insecurity on Obesity in Preschool Children," Journal of the Academy of Nutrition \& Dietetics, 112 (12), 1949-958.

Metcalf, Brad, William Henley, and Terence Wilkin (2012), "Effectiveness of Intervention on Physical Activity of Children: Systematic Review and Meta-Analysis of Controlled Trials with Objectively Measured Outcomes (Early Bird 54)," BMJ, 345 (7876), 16-26.

Mischel, Harriet N., and Walter Mischel (1983), "The Development of Children's Knowledge of Self-Control Strategies," Child Development, 54 (3), 603-19.

Mischel, Walter, Ozlem Ayduk, Marc G. Berman, B. J. Casey, Ian H. Gotlib, John Jonides, Ethan Kross, Theresa Teslovich, Nicole L. Wilson, Vivian Zayas, and Yuichi Shoda (2011), "'Willpower' Over the Life Span: Decomposing Self-Regulation," Social Cognitive \& Affective Neuroscience, 6 (2), 252-56.

Moag-Stahlberg, Alicia (2011), "The State of Family Nutrition and Physical Activity - Are We Making Progress?" Kids Eat Right Report, Chicago, IL: American Dietetic Association. 
Moisio, Risto, and Mariam Beruchashvili (2010), "Questing for Well-Being at Weight Watchers: The Role of the Spiritual-Therapeutic Model in a Support Group," Journal of Consumer Research, 36 (5), 857-75.

Monteiro Gaspar, Marisa J., Teresa F. Amaral, Bruno M. P. M. Oliveira, and Nuno Borges (2011), "Protective Effect of Physical Activity on Dissatisfaction with Body Image in Children - A Cross-Sectional Study," Psychology of Sport \& Exercise, 12 (5), 563-69.

Moore, Elizabeth S., and Richard J. Lutz (2000), "Children, Advertising, and Product Experiences: A Multimethod Inquiry," Journal of Consumer Research, 27 (1), 31-48. (1988), "Intergenerational Influences in the Formation of Consumer Attitudes and Beliefs about the Marketplace: Mothers and Daughters," Advances in Consumer Research, $15(1), 461-67$.

Moore, Elizabeth S., and Victoria J. Rideout (2007), "The Online Marketing of Food to Children: Is It Just Fun and Games?" Journal of Public Policy \& Marketing, 26 (2), 202-20.

Moore, Elizabeth S., William L. Wilkie, and Richard J. Lutz (2002), "Passing the Torch: Intergenerational Influences as a Source of Brand Equity," Journal of Marketing, 66 (2), 1737.

Moore, Lucas, Carole Harris, and Andrew Bradlyn (2012), "Exploring the Relationship between Parental Concern and the Management of Childhood Obesity," Maternal \& Child Health Journal, 16 (4), 902-08.

Morrison, Halley, Thomas G. Power, Theresa Nicklas, and Sheryl O. Hughes (2013), "Exploring the Effects of Maternal Eating Patterns on Maternal Feeding and Child Eating," Appetite, 63, 77-83. 
Morrissey, Taryn W., Rachel E. Dunifon, and Ariel Kalil (2011), "Maternal Employment, Work Schedules, and Children's Body Mass Index," Child Development, 82 (1), 66-81.

Mukhopadhyay, Anirban, and Gita V. Johar (2005), "Where There Is a Will, Is There a Way? Effects of Lay Theories of Self-Control on Setting and Keeping Resolutions," Journal of Consumer Research, 31 (4), 779-86.

Mukhopadhyay, Anirban, Jaideep Sengupta, and Suresh Ramanathan (2008), "Recalling Past Temptations: An Information-Processing Perspective on the Dynamics of Self-Control," Journal of Consumer Research, 35 (4), 586-99.

Mukhopadhyay, Anirban, and Catherine W.M. Yeung (2010), "Building Character: Effects of Lay Theories of Self-Control on the Selection of Products for Children," Journal of Marketing Research, 47 (2), 240-50.

Mushi-Brunt, Christina, Debra Haire-Joshu, and Michael Elliott (2007), "Food Spending Behaviors and Perceptions are Associated with Fruit and Vegetable Intake among Parents and Their Preadolescent Children," Journal of Nutrition Education \& Behavior, 39 (1), 2630.

Nader, Philip R., Robert H. Bradley, Renate M. Houts, Susan L. McRitchie, and Marion O'Brien (2008), "Moderate-To-Vigorous Physical Activity From Ages 9 to 15 Years," Journal of the American Medical Association, 300 (3), 295-305.

Nenkov, Gergana Y., J. Jeffrey Inman, and John Hulland (2008), "Considering the Future: The Conceptualization and Measurement of Elaboration on Potential Outcomes," Journal of Consumer Research, 35 (1), 126-41. 
Neumark-Sztainer, Dianne, Peter J. Hannan, Mary Story, Jillian Croll, and Cheryl Perry (2003), "Family Meal Patterns: Associations with Sociodemographic Characteristics and Improved Dietary Intake among Adolescents," Journal of the American Dietetic Association, 103 (3), 317-22.

Neumark-Sztainer, Dianne, Melanie Wall, Jess Haines, Mary Story, and Marla E. Eisenberg (2007), "Why Does Dieting Predict Weight Gain in Adolescents? Findings From Project EAT-II: A 5-Year Longitudinal Study," Journal of the American Dietetic Association, 107 (3), 448-55.

Neumark-Sztainer, Dianne, Melanie Wall, Mary Story, and Jayne A. Fulkerson (2004), "Are Family Meal Patterns Associated with Disordered Eating Behaviors among Adolescents?" Journal of Adolescent Health, 35 (5), 350-59.

Neumark-Sztainer, Dianne, Katherine W. Bauer, Sarah Friend, Peter J. Hannan, Mary Story, and Jerica M. Berge (2010), "Family Weight Talk and Dieting: How Much Do They Matter for Body Dissatisfaction and Disordered Eating Behaviors in Adolescent Girls?" Journal of Adolescent Health, 47 (3), 270-76.

Ng, Marie and (142 Co-Authors), (2014), "Global, Regional, and National Prevalence of Overweight and Obesity in Children and Adults during 1980-2013: A Systematic Analysis for the Global Burden of Disease Study 2013," The Lancet, 384 (9945), 766-781.

O'Connor, Teresia M., Russell Jago, and Tom Baranowski (2009), "Engaging Parents to Increase Youth Physical Activity: A Systematic Review," American Journal of Preventive Medicine, 37 (2), 141-49. 
O'Dougherty, Maureen, Mary Story, and Leslie Lytle (2006), "Food Choices of Young AfricanAmerican and Latino Adolescents: Where Do Parents Fit In?" Journal of the American Dietetic Association, 106 (11), 1846-50.

O'Dougherty, Maureen, Mary Story, and Jamie Stang (2006), "Observations of Parent-Child CoShoppers in Supermarkets: Children's Involvement in Food Selections, Parental Yielding, and Refusal Strategies," Journal of Nutrition Education \& Behavior, 38 (3), 183-88.

Ogden, Cynthia L., Margaret D. Carroll, Brian K. Kit, and Katherine M. Flegal (2012), "Prevalence of Obesity and Trends in Body Mass Index among U.S. Children and Adolescents, 1999-2010," Journal of the American Medical Association, 307 (5), 483-90. Ogden, Jane, Phillipa Cordey, Laura Cutler, and Hayley Thomas (2013), "Parental Restriction and Children's Diets: The Chocolate Coin and Easter Egg Experiments," Appetite, 61 (1), $36-44$.

Ogden, Jane, Rebecca Reynolds, and Andrea Smith (2006), "Expanding the Concept of Parental Control: A Role for Overt and Covert Control in Children's Snacking Behaviour?” Appetite, 47 (1), 100-06.

Olshansky, S. J., Douglas J. Passaro, Ronald C. Hershow, Jennifer Layden, Bruce A. Carnes, Jacob Brody, Leonard Hayflick, Robert N. Butler, David B. Allison, and David S. Ludwig (2005), "A Potential Decline in Life Expectancy in the United States in the $21^{\text {st }}$ Century," New England Journal of Medicine, 352 (11), 1138-145.

Olson, Steve (2011), Toward an Integrated Science of Research on Families, workshop report, Washington, DC: Institute of Medicine and National Research Council. 
Omar, Mildred A., Gayle Coleman, and Sharon Hoerr (2001), "Healthy Eating for Rural LowIncome Toddlers: Caregivers' Perceptions," Journal of Community Health Nursing, 18 (2), 93-106.

Owens, Laura, Charlie Lewis, Susan Auty and Moniek Buijzen (2013), “Is Children’s Understanding of Nontraditional Advertising Comparable to Their Understanding of Television Advertising?," Journal of Public Policy \& Marketing, 32 (2), 195-206.

Park, Ji K., and Deborah R. John (2014), "I Think I Can, I Think I Can: Brand Use, Selfefficacy, and Performance," Journal of Marketing Research, 51 (2), 233-47.

Peracchio, Laura A. (1992), "How Do Young Children Learn To Be Consumers? A ScriptProcessing Approach," Journal of Consumer Research, 18 (4), 425-40.

Pettigrew, Simone, and Melanie Pescud (2013), "Investigating Parents' Food-Provision Behaviours via the Sensitisation Method," Appetite, 65, 117-24.

Pew Research Center (2011), "Minorities Account for Nearly all U.S. Population Growth," http://www.pewresearch.org/daily-number/minorities-account-for-nearly-all-u-s-populationgrowth/.

Pierce, Jeanne W., and Jane Wardle (1993), "Self-Esteem, Parental Appraisal and Body Size in Children," Journal of Child Psychology and Psychiatry, 34 (7), 1125-136.

Pike, Kathleen M., and Judith Rodin (1991), "Mothers, Daughters, and Disordered Eating," Journal of Abnormal Psychology, 100 (2), 198-204.

Pliner, Patricia, and E. Ruth Loewen (1997), "Temperament and Food Neophobia in Children and their Mothers," Appetite, 28 (3), 239-54. 
Pocock, Maggie, Daksha Trivedi, Wendy Wills, Frances Bunn, and Josefine Magnusson (2010), "Parental Perceptions Regarding Healthy Behaviours for Preventing Overweight and Obesity in Young Children: A Systematic Review of Qualitative Studies," Obesity Reviews, $11(5), 338-53$.

Polivy, Janet (1996), "Psychological Consequences of Food Restriction," Journal of the American Dietetic Association, 96, 589-92.

Potter, Caroline M., and Stanley J. Ulijaszek (2013), "Predicting Adult Obesity from Measures in Earlier Life," Journal of Epidemiology and Community Health, 67 (12), 1032-037.

Prichard, Ivanka, Kellie Hodder, Amanda Hutchinson, and Carlene Wilson (2012), "Predictors of Mother-Daughter Resemblance in Dietary Intake. the Role of Eating Styles, Mothers' Consumption, and Closeness," Appetite, 58 (1), 271-76.

Pugliese, John, and Barbara Tinsley (2007), "Parental Socialization of Child and Adolescent Physical Activity: A Meta-Analysis," Journal of Family Psychology, 21 (3), 331-43.

Puhl, Rebecca M., and Janet D. Latner (2007), "Stigma, Obesity, and the Health of the Nation's Children," Psychological Bulletin, 133 (4), 557-80.

Raghubir, Priya, and Aradhna Krishna (1999), "Vital Dimensions in Volume Perception: Can the Eye Fool the Stomach?" Journal of Marketing Research, 36 (3), 313-26.

Ramanathan, Suresh, and Patti Williams (2007), "Immediate and Delayed Emotional Consequences of Indulgence: The Moderating Influence of Personality Type on Mixed Emotions," Journal of Consumer Research, 34 (2), 212-23.

Rausch, John C., Emily R. Perito, and Patricia Hametz (2011), "Obesity Prevention, Screening, and Treatment: Practices of Pediatric Providers since the 2007 Expert Committee Recommendations," Clinical Pediatrics, 50 (5), 434-41. 
Raynor, Hollie A., Emily L. Van Walleghen, Kathrin M. Osterholt, Chantelle N. Hart, Elissa Jelalian, Rena R. Wing, and Gary S. Goldfield (2011), "The Relationship between Child and Parent Food Hedonics and Parent and Child Food Group Intake in Children with Overweight/Obesity," Journal of the American Dietetic Association, 111 (3), 425-30. Redden, Joseph P., and Kelly L. Haws (2013), "Healthy Satiation: The Role of Decreasing Desire in Effective Self-Control," Journal of Consumer Research, 39 (5), 1100-114.

Reed, Danielle R., Alexander A. Bachmanov, Gary K. Beauchamp, Michael G. Tordoff, and R. Arien Price (1997), "Heritable Variation in Food Preferences and Their Contribution to Obesity," Behavior Genetics, 27 (4), 373-87.

Reedy, Jill, and Susan Krebs-Smith (2010), "Dietary Sources of Energy, Solid Fats, and Added Sugars among Children and Adolescents in the United States," Journal of the American Dietetic Association, 110 (10), 1477-484.

Rhee, Kyung E., Julie C. Lumeng, Danielle P. Appugliese, Niko Kaciroti, and Robert H. Bradley (2006), "Parenting Styles and Overweight Status in First Grade," Pediatrics, 117 (6), 2047054.

Rhee, Kyung E., Rebecca McEachern, and Elissa Jelalian (2014), "Parent Readiness to Change Differs for Overweight Child Dietary and Physical Activity Behaviors," Journal of the Academy of Nutrition \& Dietetics, 114 (10), 1601-610.

Richins, Marsha L. and Lan Nguyen Chaplin (2015), "Material Parenting: How the Use of Goods in Parenting Fosters Materialism in the Next Generation," Journal of Consumer Research, 41 (6), 1333-357.

Rideout, Victoria J., Ulla G. Foehr, and Donald F. Roberts (2010), Generation M2: Media in the Lives of 8 to 18 Year-Olds, Menlo Park, CA: Henry J. Kaiser Foundation. 
Rimal, Rajiv N. (2003), "Intergenerational Transmission of Health: The Role of Intrapersonal, Interpersonal, and Communicative Factors," Health Education \& Behavior, 30 (1), 10-28.

Robinson, Thomas N., and Donna M. Matheson (2012), "Environmental Interventions to Reduce Overeating in Children," in Food and Addiction - A Comprehensive Handbook, ed. Kelly D. Brownell, and Mark S. Gold. New York, NY: Oxford University Press, 388-93.

Roedder, Deborah L. (1981), "Age Differences in Children's Responses to Television Advertising: An Information-Processing Approach," Journal of Consumer Research, 8 (2), 144-53.

Rollins, Brandi Y., Eric Loken, Jennifer S. Savage, and Leann L. Birch (2014), "Effects of Restriction on Children's Intake Differ by Child Temperament, Food Reinforcement, and Parent's Chronic Use of Restriction," Appetite, 73, 31-9.

Rolls, Barbara J., Dianne Engell and Leann L. Birch (2000), "Serving Portion Size Influences 5Year-Old but Not 3-Year-Old Children's Food Intakes," Journal of the American Dietetic Association, 100 (2), 232-34.

Ronka, Anna, and Pirjo Korvela (2009), "Everyday Family Life: Dimensions, Approaches, and Current Challenges," Journal of Family Theory \& Review, 1 (2), 87-102.

Sallis, James F. and Karen Glanz (2006), "The Role of Built Environments in Physical Activity, Eating and Obesity in Childhood," Future of Children, 16 (1), 89-108.

Salvy, Sarah-Jeanne, Kayla de la Haye, Julie C. Bowker and Roel C.J. Hermans (2012), “Influence of Peers and Friends on Children's and Adolescents' Eating and Activity Behaviors," Physiology \& Behavior, 106, 369-78. 
Saunders, Julie, Clare Hume, Anna Timperio, and Jo Salmon (2012), "Cross-Sectional and Longitudinal Associations between Parenting Style and Adolescent Girls' Physical Activity," The International Journal of Behavioral Nutrition and Physical Activity, 9 (141), 1-11. Savage, Jennifer S., Jennifer O. Fisher, and Leann L. Birch (2007), "Parental Influence on Eating Behavior: Conception to Adolescence," Journal of Law, Medicine \& Ethics, 35 (1), 22-34. Savage, Jennifer S., Jennifer O. Fisher, Michele Marini, and Leann L. Birch (2012), "Serving Smaller Age-Appropriate Entree Portions to Children Aged 3-5 Years Increases Fruit and Vegetable Intake and Reduces Energy Density and Energy Intake at Lunch," American Journal of Clinical Nutrition, 95 (2), 335-41.

Schachter, Stanley (1968), "Obesity and Eating - Internal and External Cues Differentially Affect the Eating Behavior of Obese and Normal Subjects," Science, 161 (3843), 751-56.

Schmeer, Kammi K. (2012), "Family Structure and Obesity in Early Childhood," Social Science Research, 41 (4), 820-32.

Scott, Maura L., Stephen M. Nowlis, Naomi Mandel, and Andrea C. Morales (2008), "The Effects of Reduced Food Size and Package Size on the Consumption Behavior of Restrained and Unrestrained Eaters," Journal of Consumer Research, 35 (3), 391-405.

Seligman, Hilary K., Barbara A. Laraia, and Margot B. Kushel (2010), "Food Insecurity is Associated with Chronic Disease among Low-Income NHANES Participants," Journal of Nutrition, 140 (2), 304-10.

Seligman, Martin E.P. (2006), Learned Optimism, New York, NY: Vintage.

Senguttuvan, Umadevi, Shawn D. Whiteman, and Alexander C. Jensen (2014), "Family Relationships and Adolescents' Health Attitudes and Weight: The Understudied Role of Sibling Relationships," Family Relations, 63 (3), 384-96. 
Sillars, Alan L. (1995), "Communication and Family Culture," in Explaining Family Interactions, ed. Mary Anne Fitzpatrick, and Anita L. Vangelisti, Thousand Oaks, CA: Sage, 375-99.

Skala, Katherine, Ru-Jye Chuang, Alexandra Evans, Ann-Marie Hedberg, Jayna Dave, and Shreela Sharma (2012), "Ethnic Differences in the Home Food Environment and Parental Food Practices among Families of Low-Income Hispanic and African American Preschoolers," Journal of Immigrant \& Minority Health, 14 (6), 1014-022.

Skelton, Joseph A., Megan B. Irby, Joseph G. Grzywacz, and Gary Miller (2011), "Etiologies of Obesity in Children: Nature and Nurture," Pediatric Clinics of North America, 58 (6), 1333354.

Slater, Megan E., John R. Sirard, Melissa N. Laska, Mark A. Pereira, and Leslie A. Lytle (2011), "Relationships between Energy Balance Knowledge and the Home Environment," Journal of the American Dietetic Association, 111 (4), 556-60.

Slusser, Wendelin, Jennifer T. Erausquin, Michael Prelip, Heidi Fischer, William G. Cumberland, Fred Frankel, and Charlotte Neumann (2012), "Nutrition Knowledge and Behaviours of Low-Income Latino Parents of Preschoolers: Associations with NutritionRelated Parenting Practices," Early Child Development \& Care, 182 (8), 1041-055.

Snoek, Harriëtte M., Tatjana van Strien, Jan M.A.M. Janssens, and Rutger C.M.E. Engels (2009), "Longitudinal Relationships between Fathers', Mothers', and Adolescents' Restrained Eating," Appetite, 52 (2), 461-68. 
Spill, Maureen K., Leann L. Birch, Liane S. Roe, and Barbara J. Rolls (2010), "Eating Vegetables First: The Use of Portion Size to Increase Vegetable Intake in Preschool Children," American Journal of Clinical Nutrition, 91 (5), 1237-43. (2011), "Hiding Vegetables to Reduce Energy Density: An Effective Strategy to Increase Children's Vegetable Intake and Reduce Energy Intake," American Journal of Clinical Nutrition, 94 (3), 735-41.

St. James, Yannik, Jay M. Handelman, and Shirley F. Taylor (2011), "Magical Thinking and Consumer Coping," Journal of Consumer Research, 38 (4), 632-49.

Steinberg, Sandon A., and Richard F. Yalch (1978), "When Eating Begets Buying: The Effects of Food Samples on Obese and Nonobese Shoppers," Journal of Consumer Research, 4 (4), 243-6.

Stilley, Karen M., J. Jeffrey Inman, and Kirk L. Wakefield (2010), "Planning to Make Unplanned Purchases? The Role of In-store Slack in Budget Deviation," Journal of Consumer Research, 37 (2), 264-78.

Swinburn, Boyd, Garry Egger, and Fezeela Raza (1999), "Dissecting Obesogenic Environments: The Development and Application of a Framework for Identifying and Prioritizing Environmental Interventions for Obesity," Preventive Medicine, 29 (6), 563-70.

Sylvetsky, Allison C., Monique Hennink, Dawn Comeau, Jean A. Welsh, Trisha Hardy, Linda Matzigkeit, Deanne W. Swan, Stephanie M. Walsh, and Miriam B. Vos (2013), "Youth Understanding of Healthy Eating and Obesity: A Focus Group Study," Journal of Obesity, 2013, 1-6. 
Talukdar, Debabrata (2008), "Cost of Being Poor: Retail Price and Consumer Price Search Differences across Inner-City and Suburban Neighborhoods," Journal of Consumer Research, 35 (3), 457-71.

Talukdar, Debabrata, and Charles Lindsey (2013), "To Buy or Not to Buy: Consumers' Demand Response Patterns for Healthy versus Unhealthy Food," Journal of Marketing, 77 (2), 12438.

Tarabashkina, Liudmila, Pascale Quester and Roberta Crouch (2016), "Exploring the Moderating Effect of Children's Nutritional Knowledge on the Relationship between Product Evaluations and Food Choice," Social Science \& Medicine, 149, 145-52.

Taylor, Amanda, Carlene Wilson, Amy Slater, and Philip Mohr (2011), "Parent and Child Reported Parenting: Associations with Child Weight-related Outcomes," Appetite, 57 (3), 700-6.

Thomas, Mano J., Kalpesh K. Desai, and Satheeshkumar Seenivasan (2011), "How Credit Card Payments Increase Unhealthy Food Purchases: Visceral Regulation of Vices," Journal of Consumer Research, 38 (1), 126-39.

Topham, Glade L., Laura Hubbs-Tait, Julie M. Rutledge, Melanie C. Page, Tay S. Kennedy, Lenka H. Shriver, and Amanda W. Harrist (2011), "Parenting Styles, Parental Response to Child Emotion, and Family Emotional Responsiveness are Related to Child Emotional Eating," Appetite, 56 (2), 261-4.

Townsend, Claudia, and Wendy Liu (2012), "Is Planning Good for You? The Differential Impact of Planning on Self-Regulation," Journal of Consumer Research, 39 (4), 688-703. 
Troiano, Richard P., David Berrigan, Kevin W. Dodd, Louise Mâsse C., Timothy Tilert, and Margaret McDowell (2008), "Physical Activity in the United States Measured by Accelerometer," Medicine and Science in Sports and Exercise, 40 (1), 181-8.

Tschamler, Jillian M., Kelly M. Conn, Stephen R. Cook, and Jill S. Halterman (2010), "Underestimation of Children's Weight Status: Views of Parents in an Urban Community," Clinical Pediatrics, 49 (5), 470-6.

Van den Berg, Linda, K. Pieterse, Jamil A. Malik, Marjolein Luman, Ko Willems van Dijk, Jaap Oosterlaan, and Henriette A. Delemarre-van de Waal (2011), "Association between Impulsivity, Reward Responsiveness and Body Mass Index in Children," International Journal of Obesity, 35 (10), 1301-7.

Van Hook, Jennifer, and Kelly S. Balistreri (2007), "Immigrant Generation, Socioeconomic Status, and Economic Development of Countries of Origin: A Longitudinal Study of Body Mass Index among Children," Social Science \& Medicine, 65 (5), 976-89.

Van Ittersum, Koert, and Brian Wansink (2012), "Plate Size and Color Suggestibility: The Delboeuf Illusion's Bias on Serving and Eating Behavior," Journal of Consumer Research, $39(2), 215-28$.

van't Riet, Jonathan, Siet J. Sijtsema, Hans Dagevos, and Gert-Jan De Bruijn (2011), "The Importance of Habits in Eating Behaviour - An Overview and Recommendations for Future Research," Appetite, 57 (3), 585-96.

Variyam, Jayachandran N. (2001), "Overweight Children: Is Parental Nutrition Knowledge a Factor?" Food Review, 24 (2), 18-22. 
Vaughn, Amber E., Rachel G. Tabak, Maria J. Bryant, and Dianne S. Ward (2013), "Measuring Parent Food Practices: A Systematic Review of Existing Measures and Examination of Instruments," International Journal of Behavioral Nutrition \& Physical Activity, 10 (1), 6187.

Ventura, Alison K., and Leann L. Birch (2008), "Does Parenting Affect Children's Eating and Weight Status?" International Journal of Behavioral Nutrition and Physical Activity, 5 (15) 1-12.

Vereecken, Carine, Alisha Rovner, and Lea Maes (2010), "Associations of Parenting Styles, Parental Feeding Practices and Child Characteristics with Young Children's Fruit and Vegetable Consumption," Appetite, 55 (3), 589-96.

Videon, Tami M., and Carolyn K. Manning (2003), "Influences on Adolescent Eating Patterns: The Importance of Family Meals," Journal of Adolescent Health, 32 (5), 365-73.

Vohs, Kathleen D. and Ronald J. Faber (2007), "Spent Resources: Self-Regulatory Resource Availability Affects Impulse Buying," Journal of Consumer Research, 33 (4), 537-47. Vuorela, Nina, Marja-Terttu Saha, and Matti K. Salo (2010), "Parents Underestimate Their Child`s Overweight," Acta Paediatrica, 99 (9), 1374-9.

Wan, Echo W., and Nidhi Agrawal (2011), "Carryover Effects of Self-Control on Decision Making: A Construal-Level Perspective," Journal of Consumer Research, 38 (1), 199-214. Wang, Wenbo, Hean T. Keh, and Lisa E. Bolton (2010), "Lay Theories of Medicine and a Healthy Lifestyle," Journal of Consumer Research, 37 (1), 80-97. 
Wang, Youfa, May A. Beydoun, Ji Li, Yinghui Liu, and Luis A. Moreno (2011), "Do Children and Their Parents Eat a Similar Diet? Resemblance in Child and Parental Dietary Intake: Systematic Review and Meta-Analysis," Journal of Epidemiology and Community Health, $65(2), 177-89$.

Wansink, Brian, and Koert Van Ittersum (2003), "Bottoms Up! The Influence of Elongation on Pouring and Consumption Volume," Journal of Consumer Research, 30 (3), 455-63.

Ward, Scott (1974), "Consumer Socialization," Journal of Consumer Research, 1 (2), 1-14. Wardle, Jane, Susan Carnell, and Lucy Cooke (2005), "Parental Control over Feeding and Children's Fruit and Vegetable Intake: How are They Related?" Journal of the American Dietetic Association, 105 (2), 227-32.

Wardle, Jane, Saskia Sanderson, Carol A. Guthrie, Lorna Rapoport, and Robert Plomin (2002), "Parental Feeding Style and the Inter-Generational Transmission of Obesity Risk," Obesity Research, 10 (6), 453-62.

Warschburger, Petra, and Katja Kröller (2009), "Maternal Perception of Weight Status and Health Risks Associated with Obesity in Children," Pediatrics, 124 (1), 60-e68.

Watts, Allison W., Louise C. Mâsse, Susan I. Barr, Chris Y. Lovato, and Rhona M. Hanning (2014), "Parent-Child Associations in Selected Food Group and Nutrient Intakes among Overweight and Obese Adolescents," Journal of the Academy of Nutrition \& Dietetics, 114 (10), 1580-6.

Webber, Laura, Lucy Cooke, and Jane Wardle (2010), "Maternal Perception of the Causes and Consequences of Sibling Differences in Eating Behaviour," European Journal of Clinical Nutrition, 64 (11), 1316-22. 
Webber, Laura, Claire Hill, Lucy Cooke, Susan Carnell, and Jane Wardle (2010), "Associations between Child Weight and Maternal Feeding Styles Are Mediated by Maternal Perceptions and Concerns," European Journal of Clinical Nutrition, 64 (3), 259-65.

Wells, Jonathan C. K., Michelle Stanley, Ann S. Laidlaw, Janis M. E. Day, Mai Stafford, and Peter S. W. Davies (1997), "Investigation of the Relationship between Infant Temperament and Later Body Composition," International Journal of Obesity \& Related Metabolic Disorders, 21 (5), 400-6.

Wen, Xu, and Stanley S. Hui (2011), "Chinese Parents' Perceptions of Their Children's Weights and Their Relationship to Parenting Behaviours," Child: Care, Health \& Development, 37 (3), 343-51.

Whitbeck, Les B., and Viktor Gecas (1988), "Value Attributions and Value Transmission between Parents and Children," Journal of Marriage \& Family, 50 (3), 829-40.

White, James, and Russell Jago (2012), "Prospective Associations between Physical Activity and Obesity among Adolescent Girls: Racial Differences and Implications for Prevention," Archives of Pediatrics \& Adolescent Medicine, 166 (6), 522-7.

Whitt-Glover, Melicia, Wendell C. Taylor, Myron F. Floyd, Michelle M. Yore, Antronette K. Yancey, and Charles E. Matthews (2009), "Disparities in Physical Activity and Sedentary Behaviors among U.S. Children and Adolescents: Prevalence, Correlates, and Intervention Implications," Journal of Public Health Policy, 30, S309-34.

Wilcox, Keith, Thomas Kramer, and Sankar Sen (2011), "Indulgence or Self-control: A Dual Process Model of the Effect of Incidental Pride on Indulgent Choice," Journal of Consumer Research, 38 (1), 151-63. 
Wilkie, William L. and Elizabeth S. Moore (1999), "Marketing's Contributions to Society," Journal of Marketing, 63 (Special Millennium Issue), 198-218.

Wingert, Katherine, Drew A. Zachary, Monica Fox, Joel Gittelsohn, and Pamela J. Surkan (2014), "Child As Change Agent: The Potential of Children to Increase Healthy Food Purchasing," Appetite, 81 (1), 330-6.

Winterich, Karen P., and Kelly L. Haws (2011), "Helpful Hopefulness: The Effect of Future Positive Emotions on Consumption," Journal of Consumer Research, 38 (3), 505-24.

Wood, Wendy, and David T. Neal (2009), "The Habitual Consumer," Journal of Consumer Psychology, 19 (4), 579-92.

Zachary, Drew A., Anne M. Palmer, Sarah W. Beckham, and Pamela J. Surkan (2013), "A Framework for Understanding Grocery Purchasing in a Low-Income Urban Environment," Qualitative Health Research, 23 (5), 665-78.

Zeller, Meg H., Richard E. Boles, and Jennifer Reiter-Purtill (2008), "The Additive and Interactive Effects of Parenting Style and Temperament in Obese Youth Seeking Treatment," International Journal of Obesity, 32 (10), 1474-80.

Zlatevska, Natalina, Chris Dubelaar, and Stephen S. Holden (2014), "Sizing up the Effect of Portion Size on Consumption: A Meta-Analytic Review," Journal of Marketing, 78 (3), 14054.

Zocca, Jaclyn M., Lauren B. Shomaker, Marian Tanofsky-Kraff, Kelli M. Columbo, Gina R. Raciti, Sheila M. Brady, Melissa K. Crocker, Asem H. Ali, Brittany E. Matheson, Susan Z. Yanovski, and Jack A. Yanovski (2011), "Links between Mothers' and Children's Disinhibited Eating and Children's Adiposity," Appetite, 56 (2), 324-31. 


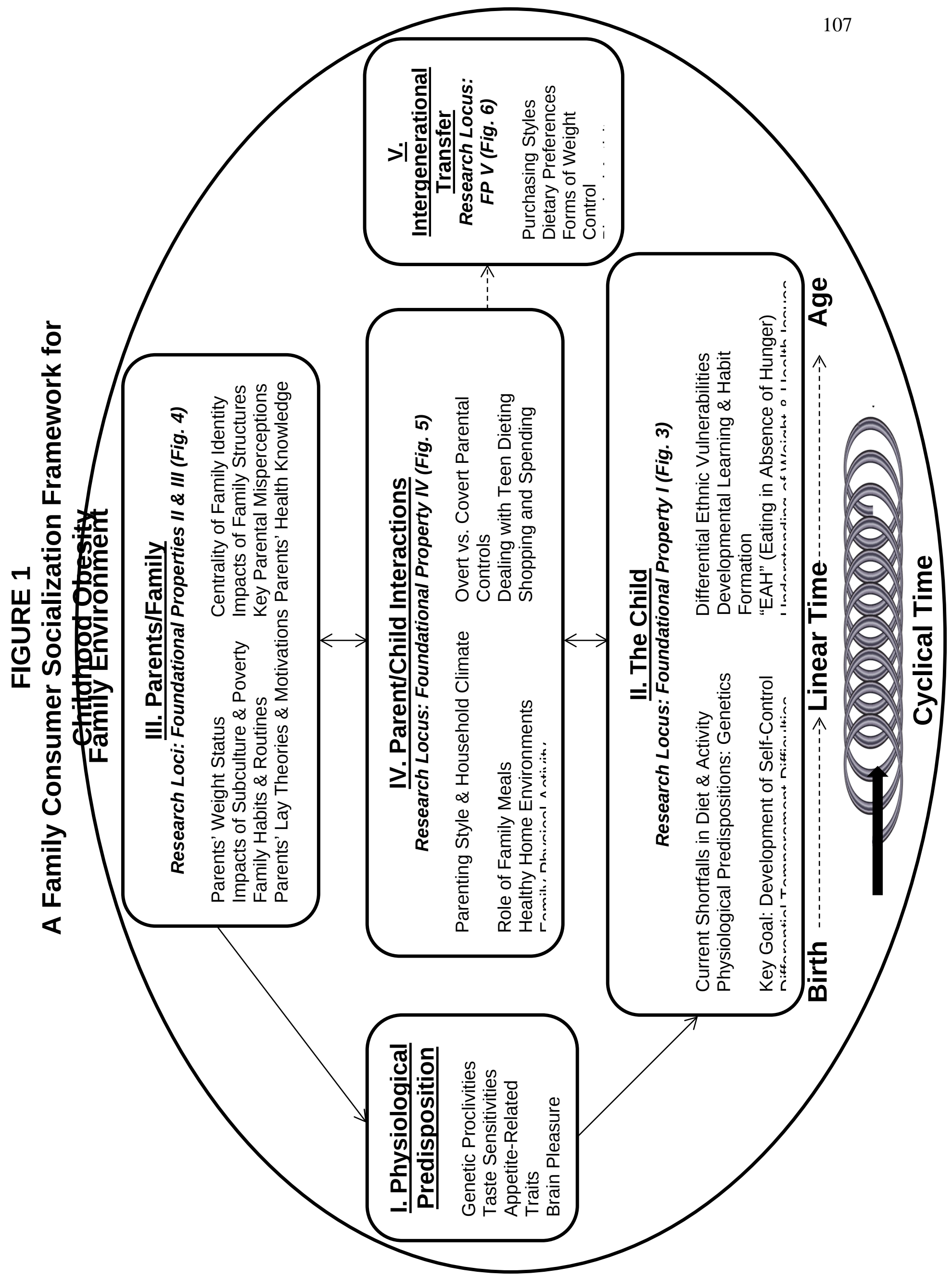


FIGURE 2

\section{U.S. CHILDHOOD OBESITY RATES BY ETHNICITY AND GENDER}
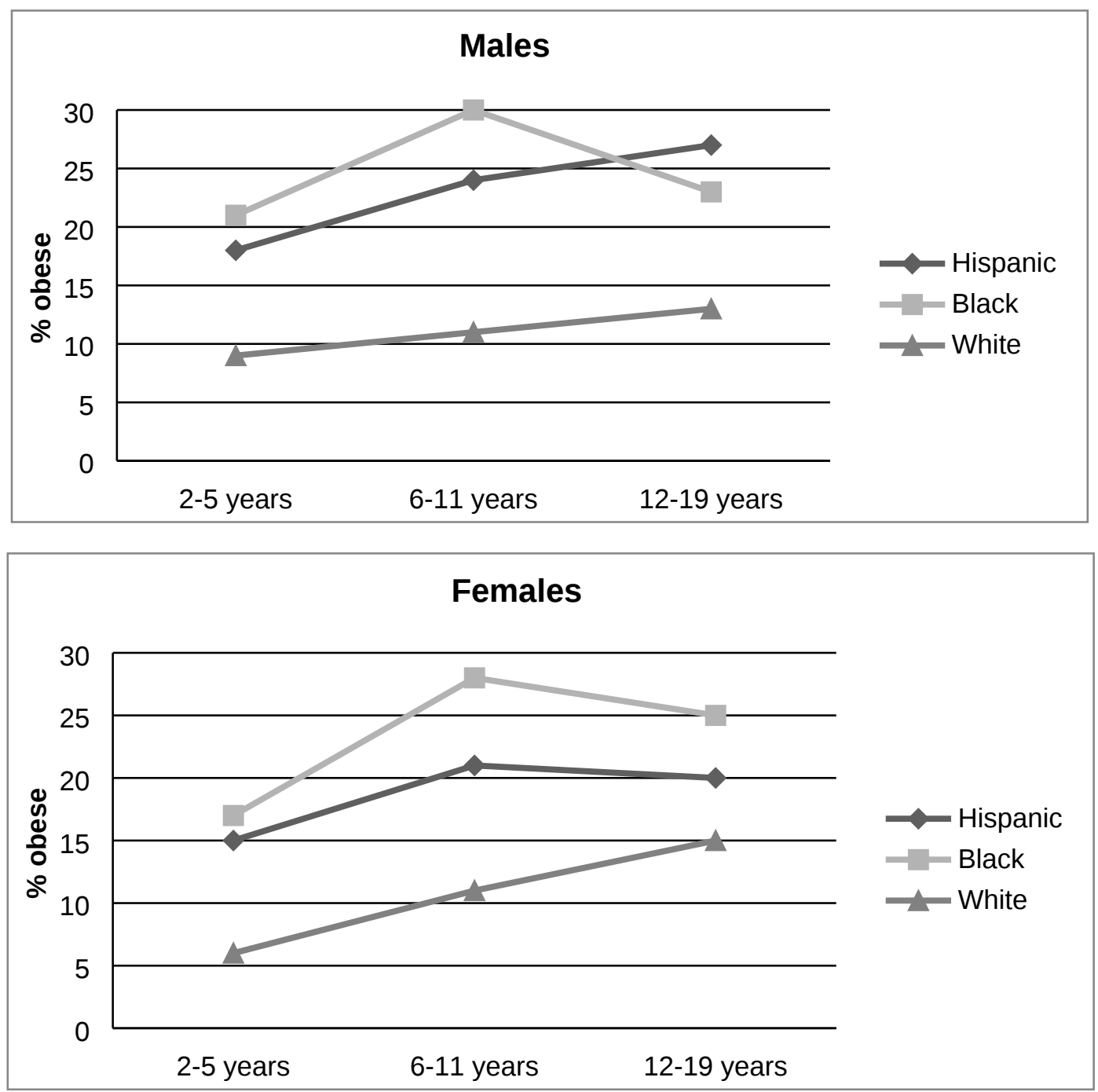
FIGURE 3

\section{FOCUSING ON THE CHILD: RESEARCH NEEDS AND OPPORTUNITIES}

\section{Foundational Property I. Child's Internalization of Healthful Consumption Habits is a Fundamental Goal}

General research need: further understanding of children's development of selfregulation strengths regarding diet and physical activity

Creation and nature of habits

Self-control as a protective factor against obesity

- Depletion of self-control

- Eating in the absence of hunger (EAH)

- Regulation of emotions

- Child dispositional characteristics: challenges from temperament

Developmental progression in children's understanding of 'overweight' and its health risks

- Age-related development of knowledge, goals and tradeoffs in decision making

- Adapting adult weight control strategies for children (age appropriate)

- Perceived locus of control for weight and health 
FIGURE 4

\title{
FOCUSING ON PARENTS AND FAMILY: RESEARCH NEEDS AND OPPORTUNITIES
}

\begin{abstract}
Foundational Property II. Household Environments Create Differential Susceptibility to Overweight
\end{abstract}

General research need: reflection of key differences in families' susceptibility to -and approaches to combatting-childhood obesity

Impacts of family structure

- Attention to father's role, sibling influence

- Nature of impacts across diverse family configurations

- Cumulative effects of family transitions (psychological, behavioral)

Challenges of poverty

- Ethnic differences

- Effects of food insecurity

- Impacts of poverty accumulation

Cultural aspects of ethnicity affecting childhood obesity

- Food preferences, dining habits and physical activity norms

- Parent transmission of food rituals, body image ideals

- Interactions with structural barriers and other environmental factors

Segmentation: (1) Cultural differences or (2) Overweight vs normal weight families

Foundational Property III. Parents' Misperceptions and Knowledge Gaps Pose Problems

General research need: exploring why many parents possess inaccurate awareness, knowledge, and perhaps motivation to combat childhood obesity in their families

Obtaining accurate misperception measures

Understanding implications of perception levels

- Lay theories as barriers in parental assessment

- Potentials for health care system discussions

- Motivation: threshold levels for parents to mitigate the problem

Parents' knowledge of nutrition and health

- Areas of gaps in understanding

- Strategies and self-efficacy

Impacts of parents' personal concerns and modeling re: weight 
FIGURE 5

\section{FOCUSING ON PARENT-CHILD INTERACTIONS: RESEARCH NEEDS AND OPPORTUNITIES}

Foundational Property IV. Parenting Practices Serve to either Foster or Protect Against Overweight

General research need: understanding what parents can do to encourage healthy lifestyles and how children respond

Dimensions of a household's emotional climate

- Weight/appearance as a sensitive issue

- Child's perceptions of parents' beliefs

- Parent facilitation of weight and health related self-efficacy

Parental style and practices that reinforce or undermine internalization

- Extend research on parental style re: both diet and physical activity

- Advance understanding of food restriction/encouragement

- Integration of parental styles and practices

- Broadening parent control options (e.g., Overt vs. Covert, adult successes)

- Children's agency: influence on parenting choices

- Children's responses to parent practices (e.g., Reactance, Dieting)

Creating a healthy home environment

- Effectiveness of 'family time' (e.g., family meals)

- Food management (e.g., portion size, parent knowledge)

- Educating children for healthful food purchasing and diet

- Parent mediation of marketing influence attempts

- Parent facilitation of physical activity

Extensions across domains

- Evolution of parent-child interactions by child's age

- Impacts of parental modeling

- Wider scope for 'parenting' (impacts of fathers, siblings and extended family) 
FIGURE 6

\section{FAMILY-RELATED WEIGHT OUTCOMES: RESEARCH NEEDS AND OPPORTUNITIES}

Foundational Property V. Roots and Sustaining Forces Supporting Childhood Obesity are Intergenerational in Nature

General research need: Expand conceptualization of IG processes pertinent to obesity

Within-family transmission of:

- Dietary, physical activity and weight management beliefs, preferences and actions

- Choice heuristics re: food, healthiness perceptions

- Weight-related stereotypes

Dynamics of IG

- Impacts of parents' own behavior

- Reverse socialization via school programs

- Factors in IG differences across families

- Temporal elements (persistence v. change)

Potentials of IG for positive health orientations and behaviors 


\section{1) CONSUMER SOCIALIZATION: ON THE ROAD TO CHILDHOOD OBESITY}

2) Childhood Consumer Socialization and the Family

2) Our Family Consumer Socialization Framework

1) I. PHYSIOLOGICAL PREDISPOSITIONS

1) II. FOCUSING ON THE CHILD

2) Developmental Considerations: Ethnic Differences and Weight across Time

2) Foundational Property I: A Child's 'Internalization' of Healthy Consumption Habits is a Fundamental Goal.

3) Developing Food and Exercise Habits: For Better or For Worse?

3) Development of Self-Control as a Protective Factor.

3) The Depletion of Self-Control: Use of EAH.

3) Managing Emotions in Self-Control.

3) Dispositional Difficulties in Self-Control: The Concept of Temperament.

2) Developmental Progression in Children's Understanding of Weight and Health.

1) III. FOCUSING ON PARENTS AND FAMILY

2) Family Identity

2) Foundational Property II: Household Environments Create Differential Susceptibility to Overweight.

3) Family Structure.

3) Living in Poverty.

3) Cultural Impacts and Segmentation Research.

2) Foundational Property III: Parents' Misperceptions and Knowledge Gaps Pose Serious Problems.

3) Parents' Misperceptions of Weight Status.

3) Parents' Knowledge and Beliefs about Healthy Households. 


\section{1) IV. FOCUSING ON PARENT-CHILD INTERACTIONS}

2) Foundational Property IV: Parenting Practices Serve to Either Foster or Protect Against Overweight.

3) The Importance of a Household's Emotional Climate.

3) 'Parental Style' Sets the Household's Emotional Climate.

3) Parenting Practices: Restricting Children's Consumption of Unhealthy Foods.

3) Parenting Practices: Encouraging Children to Eat Healthy Foods.

3) A Useful Distinction: Overt versus Covert Parental Controls.

3) Encouraging Adolescents to Diet.

2) Creating a Healthy Home Environment

3) Scheduling Family Meals.

3) Perceptual Food Management.

3) Food Purchasing.

3) Parents' Mediation of Marketing Influence Attempts.

3) Parenting and Children's Physical Activity.

3) Extensions across Domains.

1) V. INTERGENERATIONAL TRANSFER

2) Foundational Property V: The Roots and Sustaining Forces Supporting Childhood Obesity are Intergenerational in Nature.

2) Carrying Forward into Adulthood

1) CONCLUSION

2) Project Goals and Conceptual Foundations

2) Limitations

2) Into the Future 